\title{
ACTOS, ACTAS Y PROYECTOS CONSTITUCIONALES PARA LA FORJA DE LA REPÚBLICA DE COLOMBIA: DE EL SOCORRO A CÚCUTA (1810-1821)
}

\section{FACTS, ACTS AND CONSTITUTIONAL PROJECTS FOR THE FORGING OF REPUBLIC OF COLOMBIA: FROM EL SOCORRO TO CÚCUTA (1810-1821)}

\author{
Justo Cuño Bonito ${ }^{1}$ \\ Universidad Pablo de Olavide, Sevilla, España
}

\begin{abstract}
SUMARIO: I. PREÁMBULO: LAS CONSTITUCIONES, LA GUERRA Y LA FORJA DE LA NACIÓN. II. TRIBUTO, ESCLAVITUD, MUJERES Y DERECHOS POLÍTICOS. III. ESPACIOS POLÍTICOS Y RESTRICCIONES A LA REPRESENTACIÓN: ANTECEDENTES A LAS CONSTITUCIONES DE AMÉRICA DEL SUR. IV. IDEOLOGÍAS SOBRE PARTICIPACIÓN CIUDADANA EN LOS DISCURSOS POLÍTICOS DE LA INDEPENDENCIA. V. REPRESENTACIÓN POLÍTICA EN LAS PRIMERAS CONSTITUCIONES DE AMÉRICA DEL SUR. 5.1. Quito y el primer proceso constituyente. 5.2. Caracas y el primer proceso constituyente. 5.3. Mérida y Trujillo: constituciones y contextos. 5.4. Santa Fe: desde el monarquismo hasta el independentismo. 5.5. Tunja: entre las amenazas internas y externas. 5.6. De Cartagena de Indias a Cúcuta: de la incertidumbre a la consolidación en el poder.
\end{abstract}

Resumen: La forja de los nuevos Estados fue un proceso cruento, donde el cambio de estructuras y superestructuras alumbró nuevos Estados liberales construidos a partir de la derrota de las monarquias absolutas. No hubo negociación, ni transición, ni consenso: la eclosión de los proyectos constitucionales acompañó un triunfo militar que lo asentó y consolidó en torno a unas nuevas bases políticas. La nueva élite triunfante se sirvió de las cartas magnas para consolidar su nueva dominación hacia el interior de sus territorios, pero también utilizaron las constituciones para asegurar su independencia frente al resto de élites regionales. El proceso de construcción de los nuevos Estados ha sido siempre observado solo desde ópticas jurídicas o solo desde perspectivas históricas, sin interrelacionar unos factores que sólo adquieren significación y lógica a través de una óptica integradora. Esto es lo que propone la presente investigación, que forma parte de un esfuerzo iniciado hace años por construir explicaciones integradoras en torno a los proyectos constitucionales que surgieron en la capitanía general de Venezuela y en el Virreinato de la Nueva Granada a principios del siglo XIX.

Abstract: The forging of the new States was a bloody process, where the change of structures and superstructures gave birth to new liberal States built from the

1 Cuño Bonito, Justo. Profesor de Historia de América de la Universidad Pablo de Olavide de Sevilla, España. Doctor en Historia de América. ResearcherID: E-8046-2017 / Scopus Author ID: 56105846000. Título del proyecto: CONNECTED WORLDS: THE CARIBBEAN, ORIGIN OF MODERN WORLD. Entidad financiadora: European Union's Horizon 2020 research and innovation programme under the Maria Sklodowska Curie grant agreement N 823846 
defeat of the absolute monarchies. There was no negotiation, no transition, no consensus: the emergence of constitutional projects accompanied a military triumph that settled and consolidated it around new political bases. The new triumphant elite used the constitutional projects to consolidate their new domination within their territories, but they also used the constitutions to ensure their independence from the rest of the regional elites. The process of construction of the new States has always been observed only from legal points of view or only from historical perspectives, without interrelating factors that only acquire significance and logic through an integrating both point of view. This is what this research proposes, which is part of an effort begun years ago to build integrative explanations around the constitutional projects that emerged in the captaincy general of Venezuela and in the Viceroyalty of New Granada at the beginning of the 19th century.

Palabras clave: Constituciones, Nueva Granada, Venezuela, Estados-nación, independencia.

Key Words: Constitutions, Nueva Granada, Venezuela, nation-states, independence.

\section{PREÁMBUlO: LAS CONSTITUCIONES, LA GUERRA Y LA FORJA DE LA NACIÓN}

La máxima expresión del juego político con que las élites pretendieron conseguir el apoyo de los sectores populares se materializó en las primeras constituciones que se elaboraron en América y que fueron precursoras de la constitución gaditana de 1812. Las constituciones, más que un instrumento jurídico, se transformaron en herramientas politicas que asegurasen la independencia de los nuevos territorios. Esas nuevas leyes de leyes se alzaron sustituyendo a las monarquias de derecho divino, pero tratando de mantener una celestial pátina, un olimpico distanciamiento, en su restrictiva y simbólica representación.

Al tiempo, en medio del conflicto político, la guerra se convirtió en otro de los motores fundamentales del cambio. En la afirmación del Estado contemporáneo fundado por las constituciones y por la guerra, el pueblo y la nación se confundian: era toda una nación y no sólo un ejército el que estaba en guerra, por lo que la guerra era una guerra popular. Del pueblo nacía el Estado moderno, la soberanía moderna y la democracia: el pueblo, en sí, se transformaba en el príncipe maquiavélico y en el forjador del Leviatán. El Estado moderno nacía de entre las ruinas del antiguo régimen a través de una guerra que daba cuerpo al pueblo, y a éste se lo daba una nación concebida desde la singularidad nacionalista de un Danton o desde la universalidad de un Robespierre o de un Bolivar.

De pronto, - escribió Carl Von Clausewitz con ocasión de la batalla de Valmy en 1792- la guerra se habia convertido en asunto del pueblo, y de un pueblo de treinta millones de habitantes que se consideraban, todos, ciudadanos del estado... La 
participación del pueblo en la guerra, en vez de un despacho o un ejército, hacía que una nación entera entrase en el juego con su peso natural. ${ }^{2}$

La patria - indicó Louis de Saint-Just "El Arcángel del Terror" - no es, de ningún modo el suelo, es la comunidad de afectos, que lleva a que, al luchar cada cual por la salvación o la libertad de lo que le es querido, la patria se sienta defendida. Si cada uno sale de su choza con su fusil en la mano, la patria se salva de inmediato. Cada cual lucha por lo que ama ... Combatir por todos no es más que se consecuencia. ${ }^{3}$

En un complejo proceso de transustanciación, el cuerpo político sustituyó al cuerpo del monarca y en su nacimiento, la nación, en su conjunto, se independizó del cuerpo del rey. ${ }^{4}$ Luis XIV entendió que la unidad rey nación era consustancial a la monarquía absoluta y de igual modo, en 1766, Luis XV defendió esta actitud ante el parlamento proclamando que:

Los derechos y los intereses de la nación, a la que se pretende convertir en un cuerpo separado del monarca, están necesariamente unidos a los míos y sólo descansan en mis manos. No admitiré que se establezca en mi reino una asociación que llevaria a que degenere en una confederación de resistencia el lazo natural de los mismos deberes y de las obligaciones comunes, ni que se introduzcan en la monarquía un cuerpo imaginario que sólo podría turbar su armonía; la magistratura no constituye en absoluto un cuerpo ni un orden separado de los tres órdenes del reino. ${ }^{5}$

Pero el nuevo Estado se fundamentará en provecho de una clase social que así se aseguraba la preservación de su poder. En la base de este nuevo orden se encontraba el predominio del derecho y de la ley que otorgaban la libertad: para Saint Just la ausencia de ley oprimia, mientras que era la existencia de leyes la que garantizaba la libertad. Por ello la primera tarea del nuevo orden y su garantía de continuidad, lo dieron la elaboración de una constitución, una declaración de derechos que, en la práctica, transferian a la ley la autoridad antes detentada por el monarca. La ley, el pueblo y la revolución fueron las figuras esenciales de la soberanía y es por ello por lo que un Estado no revolucionario era un Estado que no podía escapar de los preceptos del antiguo régimen en donde el rey continuaba ocupando el centro y ostentaba aún la unidad de su poder. En este contexto, Robespierre afirmaría: "La resistencia a la opresión es la consecuencia de los otros derechos del hombre y del ciudadano". 6

De este modo, la guerra del fusil precedía o era consecuencia de la guerra ideológica y el nuevo Estado, precursor inmediato del complejo Estado

2 Clausewitz, Karl Von, De la Guerra, Labor, Barcelona, 1994.

3 Saint - Just, Louis de, El Espiritu de la Revolución. Malinca Pocket, Buenos Aires, 1965.

4 Kantorowitz, Ernst H., Los Dos Cuerpos del Rey: Un Estudio de Teología Politica Medieval, Alianza Editorial, Madrid, 1985.

5 Guiomar, J. Y., La nation entre l'histoire et la raison, La Découverte, París, 1990.

6 Robespierre, Maximiliano, Discursos e Informes en la Convención.: Editorial Ciencia Nueva S.L., Madrid. 1968. 
contemporáneo, era su consecuencia. En esta ascensión que daban las armas resurgian la igualdad y la libertad. ${ }^{7}$

En América o en Francia, libertad e igualdad eran derechos, pero sólo realizables en las sociedades donde la ley prevalecía. La afirmación de la libertad del hombre era, al tiempo, la afirmación de la necesidad de constituir un Estado y el Estado sólo nacería a partir de su constitución. La sociedad política y en consecuencia el Estado era el lugar del bien. Robespierre, al intervenir en el debate sobre la constitución del 10 de mayo de 1793 expondría, refiriéndose a Rousseau, que

El hombre nació para la felicidad y para la libertad, y sin embargo, es esclavo y desgraciado. Es objeto de la sociedad la conservación de sus derechos y la perfección de su ser; y por todas partes la sociedad le degrada y le oprime: Ha llegado el momento de devolverle a sus verdaderos destinos; los progresos de la razón humana han preparado esta revolución, y a vosotros se os ha impuesto especialmente el deber de acelerarla: hasta aqui el arte de gobernar no ha sido más que el arte de despojar y de avasallar a la mayoria en provecho de la minoria; y la legislación, el medio de reducir a sistemas estos atentados. Los reyes y los aristócratas han sabido cumplir con su tarea; a vosotros corresponde ahora cumplir con la vuestra. Es decir, hacer a los hombres felices y libres mediante leyes ${ }^{8}$.

En este sentido, la libertad además es una virtud y como tal además de en derecho, se convertía en deber que había que preservar mediante el terror: la alianza de naturaleza, libertad, ley, virtud, terror hacian imprescindible decapitar a Luis XVI y declarar la guerra a muerte a los españoles. Aunque por distintas razones y con distintos proyectos nacionales Bolivar y Miranda son los más claros ejemplos. Miranda logró aprender bien la lección de la revolución haitiana, aunque no tuviera opción a ponerla en práctica. El lema de Toussaint Louverture y Jean-Jacques Dessalines, autores de la exitosa revolución de los esclavos haitianos fue "Koupe Tet! Boule Kay!" (iQuemar casas! ¡Cortar cabezas!”)9. Con la enseñanza teórica de la revolución francesa y la fuerza práctica de un ejército fuertemente ideologizado, el 1 de enero de 1804, cuando Dessalines creó la bandera de Haití, desgarrando la bandera tricolor de Francia, logró lo que nadie antes al frente de una revuelta de esclavos había podido hacer: condujo hasta su triunfo a la única rebelión exitosa de esclavos en la historia. ${ }^{10}$

En Francia, en este contexto ideológico, decapitar a Luis XVI era un acto cargado de universalidad: no se mataba a un tirano, sino que la tiranía entera era la decapitada. La guerra a muerte era una obligación: así lo demandaba la

7 Mairet, Gérard, "El liberalismo: presupuestos y significaciones", en Châtelet, François y Mairet, Gerard (eds.), Historia de las Ideologias (507-524), Akal, Madrid, 1989.

8 Robespierre, M., Oeuvres complètes de Maximilien Robespierre, editado por la VI Section de l'École des Hautes Etudes y la Société des Études Robespierristes, a cargo de M. Bouloiseau, G. Lefebvre y A. Soboul, Presses Universitaires de France, París (1952-2007).

9 Eslet Shoubens, Osiris, "La fraternidad, arma positiva del pueblo haitiano", en Duffard Evangelista, Irene y Rodriguez Caguana, Adriana. Atravesando Fronteras. Voces desde Haiti hacia Sudamérica, Universidad Andina Simón Bolivar, Quito, 2019. p. 68

10 Bohórquez Morán, C. L., Francisco de Miranda. Precursor de las independencias de la América Latina. Editorial de Ciencias Sociales, La Habana, 2003. 
defensa de la libertad. Frente al gobierno de la tiranía, sin ley, sin libertad, sin sociedad (sólo existe un rebaño de esclavos y de súbditos) y donde un hombre depende de otro hombre, la república (la sociedad civil y politica) es el estado de la igualdad donde un hombre vale lo mismo que otro hombre y donde soy libre sólo si mi vecino también lo es, con lo que la igualdad también supone la libertad.

Pero el fiero universalismo en la participación de todo un pueblo en guerra para construir una nación, se transformaba en la más aguda cautela al dotar a ese mismo pueblo de representación y derechos políticos. Esto es, el mismo pueblo que servía para edificar la nación y matar en su nombre, tal vez no sirviera para votar ni adquirir derechos políticos. Aquellos conspicuos representantes que generosamente dotaron a los nuevos Estados nacionales con textos constitucionales, a menudo se autoeligieron, robando el derecho a su ciudadania, a un ignorante pueblo llano (hombres y mujeres) incapaz de gobernarse a sí mismo, víctima de sus propias pasiones, que sin embargo sufragó las guerras civiles y externas y conformó los ejércitos provinciales ${ }^{11}$.

\section{TRIBUTO, ESCLAVITUD, MUJERES Y DERECHOS POLÍTICOS}

Una de las causas del conflicto de independencia y del consecuente enfrentamiento entre españoles americanos y peninsulares que más se ha remarcado, ha sido la falta de correspondencia entre el poder económico de la élite criolla y su falta de poder político. Sin embargo, no se ha valorado qué poder político correspondió al poder económico de los indígenas. La abolición del tributo indigena fue utilizada por el bando patriota y por el realista como un arma política. No en vano, el tributo indígena, en términos generales, se ha calculado en un $40 \%$ de las rentas totales coloniales. Con este tributo se costeó una parte muy importante del esfuerzo bélico de la guerra de independencia y concluida esta, continuó suponiendo, a pesar de las promesas de su abolición siempre incumplidas, un 35\% del total de las rentas fiscales del Ecuador todavía en 1830; un $39 \%$ de las rentas fiscales del Perú en 1840 y un 25\% de las rentas fiscales de Bolivia en 1880 , casi en el siglo $\mathrm{XX}^{12}$. Como se ha demostrado, en la Nueva Granada en 1810, la Junta Suprema de Santafé decretó la abolición del tributo indígena y sólo seis meses más tarde, el 12 de marzo de 1811, las Cortes de Cádiz decretaron, a su vez, la abolición del tributo indígena en todas las colonias

11 Cuño Bonito, Justo y Carrillo García, Germán, "Sobre la élite que forjó la nación latinoamericana y las fronteras a los derechos de ciudadanía (1778-1823)", en Soto Acosta, Willy. Repensar las fronteras, la integración regional y el territorio. Buenos Aires: CLACSO, 2017, p. 29.

12 Marchena Fernández, Juan. "Los pueblos andinos en su largo camino de siglos por la tierra y el respeto a su identidad", en Lucía Provencio (Ed.) Abarrotes: la construcción social de las identidades colectivas en América Latina, Universidad de Murcia, 2006, págs. 24 y ss.

Sánchez Albornoz, Nicolás. "Tributo abolido, tributo repuesto. Invariantes económicas en la Bolivia republicana” en Halperin Donhi, Tulio, el ocaso del orden colonial en Hispanoamérica, Buenos Aires, 1978 y Guerrero, Gustavo S., Documentos históricos de los hechos ocurridos en Pasto en la guerra de Independencia, Pasto, Imprenta del Departamento, 1912, pp. 52-53.

Gutiérrez Ramos, Jairo “Acción política y redes de solidaridad étnica entre los indios de Pasto en tiempos de la independencia”, Dossier. Siglo XIX: sociedad, politica y religión, Historia Crítica, enero - junio 2007, Páginas 10-37.

Gutiérrez Ramos, Jairo "La constitución de Cádiz en la provincia de Pasto, Virreinato de la Nueva Granada, 1812-1822”, Revista de Indias, 2008, vol. LXVIII, núm. 242, Págs. 207-224. 
españolas del territorio americano. Sin embargo, con la restauración del absolutismo se restableció y aunque en mayo de 1820 Bolivar optó por mantenerlo, el tributo, pocos dias más tarde, considerando que los tributos adeudados por los indios cundinamarqueses eran incobrables, determinó anularlo en su totalidad hasta junio de 1819. Desde entonces y hasta que fue abolido en la constitución de Cúcuta, el tributo indígena se contabilizó nuevamente como recurso fiscal. Pese a que, según datos de José Manuel Restrepo, en 1828 el tributo indigena suponía sólo el 1.5\% de los ingresos corrientes del fisco neogranadino, los patriotas se negaron a eliminarlo por lo menos hasta que una nueva legislación obligara a los indios a contribuir en alguna forma. Sólo en la época de la República de la Nueva Granada en 1832, con José María Obando, el tributo fue definitivamente abolido. ${ }^{13}$

En Estados Unidos el texto constitucional excluyó de capacidad de elección y representación a todos los indios que no pagasen impuestos. También fueron excluidos los esclavos de todos los textos constitucionales. En el caso de la abolición de la esclavitud y pese a las promesas de libertad realizadas durante el conflicto de independencia, ni la Revolución norteamericana de 1776 ni la francesa de 1789, pese a su ideología liberal, democrática e igualitaria, terminaron con la trata de esclavos. El fin de la trata no se comenzó a legislar en la Gran Colombia hasta 1821 en el Congreso de Cúcuta (Ley 7 de 21 de julio de 1821, sobre libertad de partos, manumisión y abolición del tráfico de esclavos), en Argentina desde el convenio de 1839 a la constitución de 1853, en México hasta 1837 y en Perú hasta 185014. Extinguida la Gran Colombia, los países que la habian conformado, reinstauraron el sistema esclavista: en Venezuela no quedó definitivamente abolida hasta 1854 y en Nueva Granada, hasta $1852^{15}$.

Igualmente fueron excluidas de derechos politicos las mujeres. En Francia, las Furias de la Guillotina que defendieron la revolución contra los realistas o los tenderos, artesanos o campesinos que, en Valmy, en 1792 derrotaron a las tropas prusianas, quedaron excluidos de poder ejercer derechos de representación política e incluso de ser sujetos de derechos politicos. Las mujeres, los pulperos, los analfabetos, los desposeídos, los indios o los negros que lucharon contra las tropas realistas, todas y todos aquellos que no disfrutaron de propiedades, tampoco gozaron de derechos políticos. En Francia no fue sino hasta 1791 en que Olympe de Gouges, al proclamar la "Declaración de los Derechos de la Mujer y la Ciudadana" inició un proceso de conquista de los derechos políticos de las mujeres burguesas donde también en este caso, la gran mayoria de las mujeres (de clase no burguesa) quedó excluida de participación y representación política. 16

13 Ley de 11 de octubre de 1821, en: Codificación Nacional de todas las leyes de Colombia desde el año de 1821, Bogotá: Imprenta Nacional, 1924, tomo 1, pp. 116-118.

14 Cuño Bonito, Justo, "Los nuevos Estados nacionales y los debates en torno a la abolición de la esclavitud en América Latina: 1815-1860", en Naranjo Orovio, Consuelo, Esclavitud y diferencia racial en el Caribe hispano, Doce Calles, Madrid, 2017, p. 185

15 Ali, Omar H. Abolicionismo en América: Hacia un Estudio Comparativo de Historia Mundial, Pontificia Universidad Javeriana, Bogotá, 2005.

16 Arias Bautista, María Teresa, "Los Principios de Olympe de Gouges: culminación de una ideología revolucionaria", Revista Internacional de Culturas y Literaturas, Grupo de Investigación y Escrituras, Universidad de Sevilla, $\mathrm{n}^{\circ}$ 1, 2012, pp. 2-7. 


\section{Y es que}

El hábito -indicó Nicolás de Condorcet "El volcán dormido"- puede llegar a familiarizar a los hombres con la violación de sus derechos naturales, hasta el extremo de que no se encontrará a nadie de entre los que los han perdido que piense siquiera en reclamarlo, ni crea haber sido objeto de una injusticia.(...) Por ejemplo, ¿no han violado todos ellos el principio de la igualdad de derechos al privar, con tanta irreflexión a la mitad del género humano del de concurrir a la formación de las leyes, es decir, excluyendo a las mujeres del derecho de ciudadania? ¿Puede existir una prueba más evidente del poder que crea el hábito incluso cerca de los hombres eruditos, que el de ver invocar el principio de la igualdad de derechos (...) y de olvidarlo con respecto a doce millones de mujeres? ${ }^{17}$

En Estados Unidos algunos Estados aprobaron el voto femenino en el siglo XIX, como Kansas (1838) o Wyoming (1869), hasta su consagración en la enmienda decimonovena a la Constitución Americana adoptada en 1920. En América Latina, después de la efimera Constitución de la Provincia de Vélez de 1853, hubo que esperar hasta el siglo XX. El primer país latinoamericano en aprobar el voto femenino fue Ecuador, en 1929. Posteriormente lo consagraron Chile (1931), Uruguay (1932), Brasil (1943), Cuba (1943), Venezuela (1946), Argentina (1947) ${ }^{18}$ y México (1947). En Colombia se estableció en 195419.

\section{ESPACIOS POLÍTICOS Y RESTRICCIONES A LA REPRESENTACIÓN: ANTECEDENTES A LAS CONSTITUCIONES DE AMÉRICA DEL SUR}

No cabe duda de que los textos constitucionales son criaturas de sus contextos sociopolíticos y económicos específicos. No vamos a desarrollar cada contexto, pero sí haremos un rápido análisis del espacio político (escaso o nulo) que las élites que elaboraron los textos constitucionales asignaron a los sectores populares que contribuyeron decisivamente a la construcción de los nuevos Estados nacionales.

La Declaración de Derechos de Virginia del 12 de junio de 1776 proclamó por primera vez que todos los hombres eran por naturaleza libres e independientes y tenían una serie de derechos inherentes de los cuales no podian ser privados. Fue el antecedente directo de la Declaración de los Derechos del Hombre y del Ciudadano de 1789 realizada por la Revolución francesa (Lafayette conocia el texto de Virginia por haber luchado en la independencia de los Estados Unidos), y de la Carta de Derechos de los Estados Unidos, que entró en vigor en 1791 en la forma de diez enmiendas a la constitución de los propios Estados Unidos. En este texto ya se recogian los derechos fundamentales del resto de textos constitucionales: el derecho al "gozo de la vida", al "gozo de la libertad", a

17 Marie-Jean-Antoine Nicolas de Caritat, marqués de Condorcet, "Essai sur l'admission des femmes au droit de cité", 1790, citado en Paule Marie Duhet, Las Mujeres y la Revolución, Peninsula, Barcelona, 1974.

18 Alegre, Maria "El voto de las mujeres en la Argentina". En Peña González, Patricia y Zamorano, Paulina, Mujeres ausentes Miradas Presentes, Universidad de Santiago de Chile, Santiago de Chile, 2002.

19 Bonilla Vélez, Gloria, "La lucha de las mujeres en América Latina: Feminismo, Ciudadanía y Derechos" Revista Palobra palabra que obra. DOI:10.32997/2346-2884-vol.8-num.8-2007-225, 2007, pp. 42 
"los medios para adquirir y poseer propiedades", a la "felicidad" y a la "seguridad"20.

La diversidad en las facultades del hombre, donde se origina el derecho de propiedad, es un obstáculo insuperable a la unanimidad de los intereses, indicó Hamilton, uno de los principales comentaristas del texto constitucional junto con Jay y Madison: el primer objeto del gobierno fue, pues, la protección de esas mismas facultades.

En sus comentarios del 23 de noviembre de 1787 Hamilton indicó que

(...) ampliando mucho el número de los electores, se corre el riesgo de que el representante esté poco familiarizado con las circunstancias locales y con los intereses menos importantes de aquéllos; y reduciéndolo demasiado, se ata al representante excesivamente a estos intereses, $y$ se le incapacita para comprender los grandes fines nacionales y dedicarse a ellos. En este aspecto, la Constitución federal constituye una mezcla feliz; los grandes intereses generales se encomiendan a la legislatura nacional, y los particulares y locales a la de cada Estado. ${ }^{21}$

Pero la Constitución de Estados Unidos de 1787 no incluyó requisitos para poder ser votante. Se indicó, eso sí, que aquellos con capacidad para votar en las elecciones a la mayor cámara de cada Estado podian también votar en las elecciones al Congreso. En este caso, las restricciones fueron adoptadas en cada uno de los Estados. Por ello y debido al rigor con que algunas élites estatales restringieron la participación política de muy amplios sectores de la población, las posteriores enmiendas a la constitución debieron limitar la capacidad de los Estados de fijar limitaciones. La decimoquinta, la decimonovena y la vigesimocuarta enmiendas impidieron que la raza, el sexo o el pago de un impuesto constituyeran requisitos para votar, tanto en las elecciones de cada Estado como en las federales. Además, la vigesimosexta enmienda estableció que los Estados, no podian fijar requisitos de edad por encima de los dieciocho años. Sin embargo, todo quedó en el papel en el que habian sido escritas. ${ }^{22}$

El otro gran referente de las constituciones americanas y europeas, la constitución francesa de 1791, también partió de un prefacio elaborado en 1789 y aprobado por la Asamblea Nacional Constituyente que llevó por título "La Declaración de los Derechos del Hombre". La primera traducción americana completa de sus 17 artículos al castellano fue obra del prócer de la independencia colombiana Antonio Nariño y fue publicada en Santa Fe de Bogotá en $1793^{23}$.

20 Rodriguez-Toubes Muñiz, Joaquín, "Los textos ingleses sobre derechos fundamentales en el siglo XIX", en Historia de los derechos fundamentales / coord. por Francisco Javier Ansuátegui Roig, José Manuel Rodríguez Uribes, Gregorio Peces-Barba Martínez, Eusebio Fernández García, Vol. 3, Tomo 3, 2007 (E1 derecho positivo de los derechos humanos. Derechos humanos y comunidad internacional), Dykinson, Madrid, 2007, pp. 201-242

21 Hamilton, A. Madison, J. y Jay J., El Federalista, Akal, Madrid, 2015.

García, José Francisco, "El control de constitucionalidad en El Federalista y los fundamentos de una sociedad libre", Revista Chilena de Derecho, Vol. 30 No 3, 2003, pp. 491-514.

22 Grau, Luis, Nosotros, el Pueblo de los Estados Unidos. La Constitución de los Estados Unidos y sus enmiendas 1787-1992, Universidad Carlos III, Madrid, 2010.

23 Gutiérrez Escudero, Antonio, "Un precursor de la emancipación americana: Antonio Nariño y Álvarez", Araucaria, Año 7, nº 13, 2015. 
Como en la de los Estados Unidos, en el artículo 2 de la declaración francesa, se enumeraron los derechos naturales e imprescriptibles del hombre considerados como aplicables en cualquier lugar y cualquier época: la libertad, la propiedad, la seguridad y la resistencia a la opresión. El principio de igualdad fue establecido en el artículo primero (la igualdad ante la hacienda pública) y en el artículo 13, y la igualdad frente a la ley, en el artículo 6 (igualdad para acceder a los cargos públicos sólo con base en las capacidades individuales). También aquí la propiedad se concibió como un derecho inviolable y sagrado (artículo 17). Según este artículo

Nadie puede ser privado de ella, excepto cuando la necesidad pública, legalmente constatada, lo exige con evidencia y con la condición de una indemnización previa y justa.

La V enmienda de los Estados Unidos, aprobada en 1791, tomó este artículo en su texto.

El sistema de elección de los diputados de la Asamblea Legislativa fue el siguiente: se clasificó a los varones franceses (como hemos indicado, las mujeres quedaron excluidas de la ciudadania) en "ciudadanos activos": los que pagaban impuestos directos equivalentes a 3 dias de trabajo, tuviesen más de 25 años y residieran desde hacía más de un año en su comarca, y "ciudadanos pasivos": quienes no pagasen impuestos. Sólo los "ciudadanos activos" pudieron elegir a los electores de su departamento. Dichos electores fueron quienes debian escoger a los diputados provinciales para la asamblea. En 1791, Francia contó con 4.298.360 ciudadanos activos que representaron el $61 \%$ de los hombres y escasamente el $15 \%$ de la población total.

Sólo frente a la de 1791 y a las posteriores, la de 1793, la Constitución de los Montañeses, tras el triunfo de cordeliers y jacobinos frente a girondinos, rompió con la existencia de requisitos previos para la participación política. Conceptos como sufragio universal, igualdad para votar o desempeñar cargos en el ámbito nacional o municipal, "derecho a la subsistencia" o a una instrucción pública tuvieron en el texto de 1793 un amparo completo. Como texto previo al texto constitucional del 93, fue redactada la Declaración de los Derechos del Hombre y del Ciudadano votada por la Convención Nacional el 23 de junio de 1793, e incorporada como preámbulo a la Constitución de 24 de junio de $1793 .{ }^{24}$

Hernández, Guillermo (Comp.), Proceso de Nariño, t. I, Bogotá, Presidencia de la República, 1984, pp. 300-350.

Blossom, Thomas, Nariño, hero of Colombian independence, University of Arizona Press, Tucson, 1967.

Martínez Ruiz Eduardo, La librería de Nariño y los Derechos del Hombre, Planeta, Bogotá, 1990.

24 Duverger, Maurice, Instituciones politicas y Derecho Constitucional, Ariel, Barcelona, 1970.

Constant de Rebecque, Benjamin, Principios de politica aplicables a todos los gobiernos, Katz Editores, Madrid, 2010.

Tulard, Jean, Fayard Jean-François y Fierro, Alfred, Historia y Diccionario de la Revolución Francesa, Cátedra, Madrid, 1989.

Bello, Eduardo, "El poder y los poderes en la Constitución de 1791”, en Bello, Eduardo (Ed.), Filosofia y Revolución, Universidad de Murcia, Murcia, 1991, pp. 35-76. 
En la Constitución de 1793 se indicó que era ciudadano con derechos políticos (Artículo 4) todo hombre nacido y domiciliado en Francia, con veintiún años cumplidos, y todo extranjero con veintiún años de edad domiciliado en Francia desde hacía un año, que viviese ahí de su trabajo, o adquiriese una propiedad, o desposase una francesa, o adoptase un niño, o alimentase a un viejo. Y en el artículo 7 se expuso que el pueblo soberano era la universalidad de los ciudadanos franceses y nombraba (Artículo 8) a sus diputados de forma directa. ${ }^{25}$

Además de las constituciones reseñadas, en Polonia, Bélgica, Grecia, Malta, Países Bajos, Suiza o Luxemburgo se redactaron textos constitucionales vinculados al auge de los nuevos Estados nacionales y a su necesidad de ordenar los nuevos entramados jurídicos a los que debían servir de fundamento. Otro de los hitos constitucionales fueron las cartas haitianas de 1801 y 1805, la última de un corte más liberal y restrictivo en cuanto a la participación politica de los habitantes de la nueva república. ${ }^{26}$

Lucas Verdú, Pablo, "Proclamación, formulación y significado de la Declaración de Derechos del Hombre y del Ciudadano de 1789", en García Herrera, Miguel Ángel (Coord.), Derechos Humanos y Revolución Francesa, Universidad del País Vasco, Bilbao, 1991, pp. 63-90.

Rodríguez Álvarez, Azucena, "Aproximación a la idea de "República" en la Francia Revolucionaria”, Revista de Estudios Políticos (Nueva época), nº 91, 1996, pp. 201-215.

Constitución Francesa de 3 de septiembre de 1791, en http://hc.rediris.es/01/Constituciones/cf1791.htm

25 Rubio Carracedo, José, "La nueva constitución política de Rigas Velestinlins", Revista de Estudios Políticos (Nueva Época), Núm. 105. Julio-Septiembre 1999, p. 295-308.

Sánchez Quiñones, Luis, "Ciudadanía, sufragio y propiedad en las Constituciones francesas de 1791 y 1793", Deusto Journal of Human Rights, No. 5/2020, 99-124.

Constitution du 24 juin 1793 en http://www.conseil-constitutionnel.fr/conseilconstitutionnel/francais/la-constitution/les-constitutions-de-la-france/constitution-du-24-juin1793.5084.htm1

Declaración de Derechos del Hombre y del Ciudadano de 1793. 1877. Incluida en Les Déclarations des Droits de L'Homme et du citoyen. 1789-1791-1793-1795. 8-12, París: Sandoz et Fischbacher. Acceso el 10 de febrero de 2020. https://gallica.bnf.fr/ark:/12148/bpt6k54716008/f7.image

26 Blanco Valdés, Roberto L., La construcción de la libertad. Apuntes para una historia del constitucionalismo europeo, Alianza Editorial, Madrid, 2010.

Clavero Salvador, Bartolomé, "Constitución Europea e Historia Constitucional. El rapto de los poderes", Crónica Jurídica Hispalense: revista de la Facultad de Derecho, n 3, 2005, pp. 459478.

Chiaramonte, José Carlos, "El antiguo constitucionalismo en la historia hispanoamericana del siglo XIX", Nuevo Mundo Mundos Nuevos, [En ligne], Débats, mis en ligne le 08 octobre 2020, consultado el 03 enero 2021. URL : http://journals.openedition.org/nuevomundo/81983

Chust, Manuel, José Mejía Lequerica: diputado del Nuevo Reino de Granada a las Cortes de Cádiz, en VV.AA., La Independencia en los Países Andinos: Nuevas Perspectivas, Universidad Andina Simón Bolivar/OEI, Quito, 2004.

Chust, Manuel, y Ivanna Frasquet, "La génesis de las independencias. La complejidad de un proceso histórico de dimensiones universales", en Chust Manuel y Frasquet, Ivana (Eds.), La patria no se hizo sola. Las revoluciones de independencia iberoamericanas, Sílex, Madrid, 2012, pp. 17-66.

Chust, Manuel, 1812, El poder de la palabra, Acción Cultural Española, 2012. 


\section{IDEOLOGÍAS SOBRE PARTICIPACIÓN CIUDANA EN LOS DISCURSOS POLÍTICOS DE LA INDEPENDENCIA}

En América del Sur salvo escasas excepciones, el sistema político no asignó derechos ni representación política a los desposeídos, ni a los no propietarios, ni a los analfabetos, ni a los sirvientes, ni a los esclavos, ni a las mujeres, ni a los pobres en general. Las nuevas naciones quedaron constreñidas a un escaso 5\% de la población. Precisamente, el conflicto provocado por ese $5 \%$ conformado, entre otras, por las distintas élites provinciales, condujo irremediable y progresivamente al conflicto civil.

De todo el arsenal ideológico recibido y sistematizado, se elaboró un sistema representativo, pero censitario, que eliminase el riesgo previsible de que, en una democracia universal, el poder cayese en manos de quienes pudieran perderlo y entregarlo en manos de quienes había sido tan costoso arrancarlo. En la elaboración de los modelos de gobierno se unían así tanto los prejuicios de clase hacia los sectores populares, particularmente hacia los indigenas, como las propias experiencias de gobierno ya pasadas. Para las élites dirigentes no había peor mal que esos sectores populares, a quienes naturalmente debía refluir la acción de gobierno, pudieran llegar a perder el poder por un mal cálculo de todas las posibilidades. De este modo y en sus discursos para justificar un cuerpo de nación restringido, podian utilizar incluso los mismos argumentos en contra del pueblo llano de los que ellos abominaban por haber sido objeto desde el despotismo colonial: el recurso a un estado infantil que era preciso tutelar fue tan común en un caso como en el otro. Sin embargo, esos sectores eran necesarios, imprescindibles para consolidar un nuevo proyecto de nación. Es el sentido del Manifiesto a los Pueblos de Colombia de Antonio Zea en 1820 y su llamada general a que "haya un movimiento simultáneo y general a que contribuya cada uno cuanto más pueda a la patria, levántese la población en masa y precipítese sobre el enemigo como un torrente impetuoso que todo lo derroca y todo lo arrastra". 27

De igual modo Fernando VII al justificar el envío de tropas a América al mando del general Morillo se refirió a la necesidad de mantener unida en un solo cuerpo a esa gran familia de hermanos españoles y americanos de la cual él $y$ sólo él era el padre. ${ }^{28}$

Pero frente a todas las teorias, se suceden las verdades de los hechos reales, concretos que van conformando cada una de las sociedades americanas. Frente al juego teórico, está la realidad permanente que adoptan las élites en la construcción de los Estados nacionales a través de un uso, quizá mejorado por

Chust, Manuel, La Tribuna Revolucionaria: La Constitución de 1812 en ambos hemisferios, Sílex, España, 2014.

Kossok, Manfred, "La Independencia en América Latina”, en Roura, Lluís Y Chust, Manuel (Eds), La Ilusión Heroica. Colonialismos, Revolución e Independencias en la obra de Manfred Kossok, Servicio de Publicacions de la Universitat Jaume I, Castelló de la Plana, 2010.

27 Zea, Francisco Antonio, Manifiesto a los Pueblos de Colombia, en http://www.cervantesvirtual.com/obra/manifiesto-sobre-la-creacion-de-la-republica-decolombia--0/

28 Cuño Bonito, Justo, El Retorno del Rey, Universidad Jaume I, Castellón, 2018. 
su adaptación idónea, quizá imperfecto por su estudiosamente imperfecta asimilación:

"En un pais donde no es imposible que el pobre llegue a gobernar -indicó Alexis de Tocqueville en El Antiguo Régimen y la Revolución- al Estado, siempre resulta más fácil apartar a los pobres del gobierno que en aquellos en que no se les ofrece la esperanza del poder; pues la idea de esa grandeza imaginaria, a la que puede un día ser llamado, se sitúa constantemente entre él y el espectáculo de sus miserias reales. Es un juego de azar en el que la grandeza de la posible ganancia atrae su alma a pesar de las probabilidades de pérdida. Le gusta la aristocracia del mismo modo que la lotería" ${ }^{29}$

Dejando aparte el lado español (Juan B. Picornell y la Conjura de San Blas ${ }^{30}$, el libelo "Pan y Toros" de León de Arroyal, Lorenzo Calvo de Rosas, delegado de Zaragoza por la Junta Central), los proyectos de conformación de las nuevas sociedades americanas adolecerán, sin embargo y salvo casos excepcionales, de una visión miope del conjunto de una sociedad que sin excepciones debía construir una nueva ciudadanía. Lo posible sólo fue adoptado por unos pocos. Sólo algunos pequeños sectores medios de algunas ciudades harán alarde de su jacobinismo aterrorizando al alarmado medio social conservador en que intentaron apoyarse. En algunos casos, darán lugar a posteriores movimientos populares rurales como el liderado por Gual y España, Chirino, Tiradentes, Francisco de Miranda, José Artigas en el Río de la Plata, los hermanos Piñeres en Cartagena de Indias y Martín de Güemes en el Alto Perú.

En la Proclama a los Habitantes Libres de la América Española en 1797, atribuida a José María España y a Manuel Gual se animaba al "grande arte de hacer una revolución feliz" que debía ser puesta en marcha por los más desfavorecidos

"entre blancos, indios, pardos y negros debe haber la mayor unión: todos debemos olvidar cualquier resentimiento que subsista entre nosotros, reunirnos bajo un mismo espiritu y caminar a un mismo fin... una revolución politica, que no es otra cosa que la recuperación de los derechos del hombre, debe hacerse exclusivamente por el Pueblo: asi tener consideraciones con sus enemigos es ir contra la primera regla que se debe seguir". ${ }^{31}$

Pese a que su inicial en su inicial Proyecto de Constitución Americana de 1798 Francisco de Miranda previó un voto censitario y que sólo pudieran ser elegibles aquellos con más de 20 fanegas de tierra cultivada y renta anual de 300 pesos al menos, en su Proclama a los Pueblos de Colombia de 1806 otorgaba derechos de ciudadanía a todos los habitantes "Que los buenos e inocentes indios, así como los bizarros pardos y morenos libres crean firmemente que somos todos conciudadanos y que los premios pertenecen exclusivamente al mérito y a la virtud". 32

29 De Tocqueville, Alexis, El Antiguo Régimen y la Revolución, Alianza Editorial, Madrid, 1994.

30 Elorza, Antonio, La Ideología Liberal en la Ilustración Española, Tecnos, Madrid, 1970.

31 Grases, Pedro, La Conspiración de Gual y España y el Ideario de la Independencia, Instituto Panamericano de Geografia e Historia, Caracas, 1949.

32 Grases, Pedro, Pensamiento Politico de la Emancipación Venezolana, Biblioteca Ayacucho, 1988. 
Artigas vivió el apogeo de su prestigio entre 1813 y 1819 y en muchos de los escritos las propuestas gubernamentales aparecen sometidas al análisis de asambleas populares. Artigas insistirá siempre ante el pueblo reunido: "Mi autoridad emana de vosotros y ella cesa por vuestra presencia soberana". En las famosas "Instrucciones del año XIII" propondrá que para formalizar el pacto con las demás provincias se ponga como condición previa que se constituya un Estado federal, republicano y democrático; además debía quedar establecido, entre otras cosas, que ese Estado federal "promoverá la libertad civil y religiosa en toda su extensión imaginable". Es particularmente interesante su defensa inclaudicable de la "soberanía particular de los pueblos", el derecho de cada comunidad y cada cultura a tomar decisiones por sí misma sobre cada uno de los asuntos que le atañen, en tanto no haya delegado expresa y libremente al Gobierno Central para la resolución de un determinado tema. En el Reglamento Provisorio de 1815, decretará un reparto de tierras "de tal manera que los más infelices sean los más privilegiados". 33

Joaquim José da Silva Xavier, el Tiradentes, tropero, minero, médico de curar enfermos, dentista, alférez y conspirador fue ejecutado en 1792 por un intento de sublevación para conseguir la independencia de un Brasil que pretendía convertir en una república parlamentaria, con un parlamento en cada ciudad y uno central. Además, había previsto liberar a todos los esclavos comenzando por los mulatos, abolir los monopolios reales y decretar la libertad de comercio con otras naciones. ${ }^{34}$

En la Cartagena que había constituido su estado independiente el 11 de noviembre de 1811, los hermanos Gutiérrez de Piñeres habian tomado el poder obligando a la declaración de independencia absoluta con respecto a España. Representaban a los sectores populares fundamentalmente castas y libres de todos los colores que se oponían al continuado gobierno de la ciudad por los hacendados y comerciantes (ya fueran criollos o españoles peninsulares) que no habian resuelto crear un gobierno completamente ajeno al de la península. El gobernador Pedro Gual informó al Supremo Gobierno de la Unión que habían sido 40 o 50 hombres los que habían tomado el ayuntamiento y que éstos no

"eran los padres de familia de Cartagena, los vecinos honrados o las patriotas virtuosas. Era la hez del pueblo, una caterva de hombres oscuros, que, si casas mi familia, sin tener nada que perder, manifestaban ser los instrumentos de algunos integrantes que con más astucia no habian querido presentar la cara primero. Era por mejor decir una porción de hombres desmoralizados que habiendo servido de agentes secundarios en las diferentes escenas revolucionarias del pais, estaban sostenidos por manos poderosas impunidad era el fruto y el premio de tan criminal cooperación. De esta manera las clases más respetables de Cartagena no podido libertarse en los años pasados que los insultos y vejaciones que les hacia esta gente despreciable". 35

33 Abella, Gonzalo, Artigas el Resplandor Desconocido, Betum San Ediciones, Montevideo, 1999.

34 Ribero, Darcy. Tiradentes. Joaquin Xosé Da Silva Xavier (1746 - 1792). http://www.portalalba.org.

35 Archivo General de la Nación de Colombia, Fondo José Manuel Restrepo, Rollo 5, Documentos relativos a la ocurrencia del 17 de diciembre último y sus resultados. 
Pero salvo estas excepciones, del arsenal ideológico recibido se seleccionó un sistema representativo pero censitario que eliminase el riesgo previsible de que, en una democracia universal, el poder cayese en manos de quienes pudieran perderlo a manos de quienes había sido tan costoso arrancarlo. En la elaboración de los modelos de gobierno se unían asi tanto los prejuicios de clase hacia los sectores populares, como las propias experiencias de gobierno ya pasadas. Para las élites dirigentes no había peor mal que ellas, a quienes naturalmente debía refluir la acción de gobierno, pudieran perderlo por un mal cálculo de sus posibilidades. De este modo y en sus discursos para justificar un cuerpo de nación restringido podian utilizar incluso los mismos argumentos en contra del pueblo llano de los que ellos decían haber sido objeto desde el despotismo colonial: el recurso a un estado infantil que era preciso tutelar fue tan común en un caso como en el otro.

En esta necesidad de construir estados que tuviesen restringido el reconocimiento de los derechos naturales de toda la ciudadanía encontramos afirmaciones como las de Bolivar en su Carta de Jamaica cuando indicó que

"Los acontecimientos de la Tierra Firme nos han probado que las instituciones perfectamente representativas no son adecuadas a nuestro carácter, costumbres $y$ luces actuales... (afirmando que Venezuela) ha sido el más claro ejemplo de la ineficacia de la forma democrática y federal para nuestros nacientes estados";

o en 1819 en el discurso de Angostura cuando expuso que

"La libertad, dice Rousseau, es un alimento suculento pero de difícil digestión. Nuestros débiles conciudadanos tendrán que robustecer su espiritu mucho antes que logren digerir el saludable nutritivo de la libertad... Debemos confesarlo: los más de los hombres desconocen sus verdaderos intereses, y constantemente procuran asaltarlos en las manos de sus depositarios: el individuo pugna contra la masa, y la masa contra la autoridad";

quizá también por ello Antonio Nariño afirme en su Discurso ante el Congreso de Cúcuta que no hay que temer que todo ciudadano en el ejercicio de sus funciones debe votar y todo el que vota debe tener opción a ser elegido porque en definitiva, el gobierno acabará por ser conformado sólo "sin desórdenes por las personas más ilustradas de la sociedad, pues está en el corazón humano y lo confirma la experiencia, que jamás se da el voto a una persona que se crea inferior al que vota, y así se ve una progresión que desde los hombres más rústicos sube hasta los más ilustrados de la república"; de igual forma un Bernardo de Monteagudo desengañado, expuso en 1823 que

"El segundo principio que segui en mi administración, fue restringir las ideas democráticas: bien sabía que para traerme el aura popular, no necesitaba más que fomentarlas; pero quise hacer el peligroso experimento de sofocar en su origen la causa que en otras partes nos habia producido tantos males"36;

Hipólito Unanue convocará, en su discurso de investidura el 20 de diciembre de 1822, sólo a los miembros de las clases noble y media que habian sido apartados de la administración colonial y sólo a "los talentos extraordinarios, la constante aplicación, la sabiduría adquirida por uno y por otro no tuvieron más

36 Romero, José Luis y Romero, Luis Alberto, Pensamiento Politico de la Emancipación (17901825), Biblioteca Ayacucho, Caracas, 1977, pp. 167-176. 
premios que una dependencia inmediata de europeos orgullosos e ignorantes" 37. En este mismo sentido, el cubano José Antonio Miralla en 1820 en su escrito "Soberanía del pueblo y elecciones populares" argumentaría que

"Si nuestras elecciones de diputados fueran hechas directamente por el pueblo, como sucede entre los ingleses y americanos, y como sin duda serán cuando estemos más ilustrados en politica, serian muy sencillos los actos de soberanía, o las elecciones populares; pero el estado general de nuestros pueblos, nos ha precisado a una multitud de trámites, con la idea con conseguir mejores elecciones del voto de unos pocos individuos reescogidos para electores, que no de los sufragios de un pueblo que aún ignora cuáles son las cualidades buenas para representante, y por consiguiente, quiénes son los sujetos que las poseen."38

\section{REPRESENTACIÓN POLÍTICA EN LAS PRIMERAS CONSTITUCIONES DE AMÉRICA DEL SUR}

En toda América la disolución del modelo político colonial hasta entonces imperante conllevó la fragmentación de los dominios territoriales y la multiplicación de los poderes autónomos. La pugna entre los modelos centralista y federalista fue uno, aunque no el menor, de los conflictos suscitados en los territorios americanos. El poder real, secuestrado, perdia definitivamente su capacidad para sostener todo el andamiaje colonial. Sin embargo, al tiempo que se derrumbaba con decrépito toda su estructura, los proyectos emergentes chocaban entre sí con estrépito. El territorio se fragmentó como si estuviese conformado por numerosas placas tectónicas en un inestable océano de magma. El devenir de los acontecimientos y el ansia de prevalencia sobre el resto de los territorios hizo que las placas colisionasen entre sí en la intención de despuntar sobre el resto. ${ }^{39}$

El problema de reubicar la soberanía cuando el soberano ya no estaba provocó tantas soluciones como contextos: en el caso de la Nueva Granada las diferentes propuestas variaron entre el ejercicio individuado de las soberanias locales, o el proceso de centralización que pretendió imponer la élite santafereña ${ }^{40}$.

En la Nueva Granada, Venezuela, Ecuador, Perú, Virreinato de la Plata o Alto Perú, el conflicto de todos contra todos acabó evolucionando en favor de la pugna entre el centro y la periferia. En la Nueva Granada, la provincia de Cundinamarca, su élite, contra el resto y toda esta élite (centralista o federalista)

37 Romero, José Luis y Romero, Luis Alberto, Pensamiento Politico de la Emancipación (17901825), op. cit., pp. 186 - 190.

38 Romero, José Luis y Romero, Luis Alberto, Pensamiento Politico de la Emancipación (17901825), op. cit., pp. 257-261.

39 Cuño Bonito, Justo, "La construcción política de una compleja realidad social: Conflictos, negociaciones y acuerdos en la base del primer constitucionalismo americano, 1811-1815", en Frasquet Miguel, Ivana y García Monerris, Encarnación, Tiempo de Política, tiempo de constitución: la monarquía hispánica entre la revolución y la reacción (1780-1840), Comares, 2018, pp. 27-54.

40 Acevedo-Tarazona, Álvaro y Villamizar-Palacios, Carlos "La soberanía local durante la primera época republicana en el Nuevo Reino de Granada. Los casos de Tunja, Socorro y Mariquita, 1810-1812", HiSTOReLo. Revista de Historia Regional y Local 12 (23), 2020, pp. 157189. 
apoyada en unos sectores populares excluidos mayoritariamente de la conformación de los nuevos proyectos estatales, ajenos al juego político, pero rehenes de su resultado.

Según ha afirmado Marquardt, las constituciones maternas del año 1811 utilizaron el material de las constituciones primarias de Estados Unidos y Francia, codificadas sólo poco antes, así como los textos teóricos claves de la ilustración internacional, pero formaron con ellos una combinación particular del constitucionalismo ilustrado que delineó una familia constitucional específica. ${ }^{41}$

En el análisis de las diferentes constituciones, se hace imprescindible analizar el contexto sociopolitico en que fueron creadas porque es este el que nos da las claves para entender el verdadero trasfondo de los textos constitucionales, así como sus aspiraciones.

\subsection{Quito y el primer proceso constituyente}

En Quito en 1809 presidía la Audiencia el español peninsular, teniente general D. Manuel Urriez, conde Ruiz de Castilla, teniente general español, que se dejaba influir, entre otros, por el abogado don Tomás Aréchaga. Ya en febrero, Urriez recibió denuncias del capitán Juan Salinas sobre un hipotético plan de gobierno que se debía establecer en las provincias meridionales de la Nueva Granada, en el caso de que la España fuese subyugada por los franceses. Pese a la falta de pruebas y a que el plan no pudo darse, Salinas fue puesto en prisión junto con algunos vecinos principales de Quito. Finalmente, ninguno fue castigado, pero se estableció un clima de tensión que habría de estallar en un breve plazo. 42

En Quito, como capital de la Audiencia, tenía dos alcaldes, los cuales de manera tradicional se alternaban entre americanos y europeos: en 1.808 el alcalde primero había sido un criollo y el segundo un peninsular, pero para las elecciones de 1.809, se eligió a dos americanos con el argumento de que ningún europeo estaba calificado para ese cargo. ${ }^{43}$ Desde entonces, varios vecinos principales de Quito prepararon una revolución. La tarde del 9 de agosto de 1.809, un grupo de "notables" firmaron un acuerdo para establecer una junta integrada por 36 miembros, escogidos entre vecinos y cuyo fin era el de gobernar en nombre de Fernando VII. Las elecciones no prefiguraban ningún sistema democrático y las intenciones del procedimiento no fueron más allá de las de sancionar el orden y desigualdad propiciados por la monarquía. ${ }^{44}$

En el Ecuador el 10 de agosto de 1809 Quito constituyó su propia Junta Suprema ante la inoperancia y pasividad del presidente de la Audiencia, el viejo conde Ruiz Castilla. Las élites criollas dominaron el órgano de representación recién conformado y alegaron que la Junta Central constituida en España habia

\footnotetext{
41 Marquardt, Bernd, "Dos siglos de derechos fundamentales en Hispanoamérica (1810-2008). Exigencia y realidad desde una perspectiva global comparada", Revista Pensamiento Jurídico 23, 2008, pp. $33-72$.

42 Restrepo, José Manuel, Historia de la Revolución de Colombia, op. cit., p. 115.

43 Actas del Consejo, 1.808. Archivo Municipal de Quito

44 Vanegas Useche, Isidro, "Elecciones y orden social en Nueva Granada, de la monarquía a la república", en Anuario Colombiano de Historia Social y de la Cultura 48.1, 2021, pp. 69-93.
} 
sido edificada sin intervención de América, sin derecho alguno para dominar ésta y que así como cada una de las provincias de España de la cual había sido declarada América como parte integrante, tuvo derecho para establecer juntas que gobernaran durante la cautividad del rey, así Quito debía gozar del mismo derecho erigiendo una junta que reemplazara las autoridades nombradas en tiempos de Carlos IV y que no habian sido confirmadas por Fernando VII. Los principios que rigieron la Junta recogidos en un Acta firmada el 10 de agosto de 1809 y que fueron proclamados a las demás provincias de la presidencia de Quito y al Perú y a la Nueva Granada, fueron expuestos como moderados y siempre tendentes a conservar la religión, el rey y la patria. La Junta se atribuyó el tratamiento de Majestad y dio al presidente el de Alteza Serenísima y a los miembros el de Excelencia. Se señaló al presidente un sueldo de seis mil pesos anuales y dos mil cada uno de los miembros y se decretaron grandes uniformes para sus miembros. Para ganarse el apoyo del pueblo la Junta extinguió el estanco del tabaco, rebajó el precio del papel sellado e hizo algunas otras concesiones. ${ }^{45}$

La Junta tuvo inmediata respuesta de las provincias de Cuenca y de Guayaquil: los gobernadores respectivos, coroneles Don Melchor Aymerich y Don Bartolomé Cucalón, así como el obispo de Cuenca, Don Andrés Quitián (declarado por la Junta como su vocal nato) se declararon abiertamente contra el nuevo gobierno. El obispo, convertido en general de ejército, ofreció la renta del seminario conciliar y el patrimonio de los pobres para sostener las tropas e hizo preparativos militares. ${ }^{46}$

No fue sino hasta el 15 de febrero de 1812 cuando se promulgó la primera Constitución ecuatoriana, la Constitución del Estado de Quito, que estableció una República con división de poderes y terminó con cualquier sospecha sobre las convicciones republicanas de los quiteños. Este fue el primer Estado independiente y soberano proclamado en el territorio del Ecuador y ejerció jurisdicción sobre la Sierra central y norte, así como sobre el litoral de Esmeraldas. ${ }^{47}$

Un Congreso Constituyente se encargó de elaborar y aprobar el llamado "Pacto Solemne de Sociedad y Unión entre las Provincias que forman el Estado de Quito" y que es actualmente conocido como la Constitución Quiteña. El documento establecía una independencia con respecto a las autoridades de los virreinatos de Perú y Nueva Granada, pero continuando dentro de la monarquía hispánica 48 aunque, al tiempo, ganando un espacio propio, decisivo, para

45 Pérez Ramírez, Gustavo, Historia del Acta de la Independencia de Quito del 10 de agosto de 1809, FONSAL y Trama Ediciones Quito, Quito, 2009, p. 15.

Pérez Ramírez, Gustavo, La Revolución de Quito a la luz de nuevos documentos. 1809, Gobierno de la Provincia de Pichincha, Quito, 2010.

46 Restrepo, José Manuel, Historia de la Revolución de Colombia, op. cit. T. II, p. 120-130.

${ }^{47}$ Rodríguez, Jaime E., La Revolución Política durante la época de la independencia. El Reino de Quito. 1808-1822, Universidad Andina Simón Bolívar, Quito, 2006, pp. 70-79.

48 Morelli, Federica, "El Pacto quiteño de 1812: algunas reflexiones en torno al primer constitucionalismo ecuatoriano", en Ayala Mora, Enrique, Historia Constitucional. Estudios comparativos, Universidad Andina Simón Bolivar, Quito, 2014. 
impulsar sus intereses económicos al margen de la monarquía española. ${ }^{49}$ Aunque se detalló que la forma de gobierno sería popular y representativa (artículo 3), no se especificó a lo largo del articulado cuál sería el modo de elección ni tampoco los ciudadanos que serían considerados tales y, por ende, sujetos de derechos políticos con posibilidad de elegir y ser elegidos. Este punto es muy significativo y contrasta con el detalle con que se especificaron los sueldos de cada uno de los altos cargos del Estado (artículos 33, 44 y 45).

Tras el regreso de los españoles y con el gobierno de Toribio de Montes se desarrollaron en el Reino de Quito las primeras elecciones conforme a la Constitución Gaditana de 1812. Jaime Rodríguez concluyó que, irónicamente, el sistema político español de 1812 parecía haber sido más popular y democrático que la mayoría de los que los movimientos insurgentes implantaron en los territorios que controlaban. Los españoles, recién retomado el poder en Quito, no podian abrir un nuevo conflicto por causa de los derechos políticos asignados por la constitución, así que universalizaron el proceso electoral.

En Quito o Nueva España los insurgentes manipularon el proceso y permitieron menos participación local que los realistas. Una de las razones la expuso claramente el criollo José Manuel Restrepo, conspicuo miembro de la élite que formó parte del primer gobierno de la Nueva Granada:

"Tanto en esta provincia (Cartagena) como en las otras de la Nueva Granada se habia adoptado y continuó observándose, el método de dobles elecciones populares: los padres de familia nombraban electores y reunidos éstos en la cabecera del distrito capitular, que se llamó cantón, nombraban los diputados. Aunque tal sistema de elecciones no fuera el más popular, no podía seguirse otro, a causa de la ignorancia de los pueblos, incapaces en lo general de escoger directamente sus representantes."50

\subsection{Caracas y el primer proceso constituyente}

En la Capitanía General de Venezuela: La Junta Suprema de Caracas, que se erigió en la institución en la que refluyó la soberanía perdida por la corona, gobernó la Capitanía General de Venezuela entre el 19 de abril de 1810 (fecha de

49 Rodriguez, Jaime E., "Los orígenes de la revolución de Quito en 1809”, Procesos, Revista Ecuatoriana de Historia, No. 34 (jul. - dic. 2011), pp. 91-123.

50 Rodríguez, Jaime, "Fronteras y conflictos en la creación de las nuevas naciones en Iberoamérica", Revista Circunstancia, Año III - Número 9 - enero 2006.

También sobre el tema de las elecciones:

Annino, Antonio (Coord.), Historia de las elecciones en Iberoamérica, siglo XIX, Buenos Aires, Fondo de Cultura Económica, 1995.

Posada Carbó, Eduardo (Dir.), Elections before Democracy: The History of Elections in Europe and Latin America, Londres, MacMillan Press, 1996.

Chiaramonte, José Carlos, "Vieja y nueva representación: los procesos electorales en Buenos Aires, 1810-1820", en Annino, Antonio (Coord.), Historia de las elecciones en Iberoamérica, siglo XIX, Buenos Aires, Fondo de Cultura Económica, 1995, pp. 19-63.

Palacios, Nohora Patricia, "La elección de la república: historia de las elecciones en Colombia entre 1809-1838", tesis de doctorado en Estudios Políticos, París, École de Hautes Études en Sciences, Sociales, 2014.

Fernando Prado, David "Las mutaciones del Cabildo de Popayán en un periodo revolucionario, 1809-1811", Anuario Colombiano de Historia Social y de la Cultura 47.1, 2020, pp. 113-137. 
la renuncia obligada del capitán general Vicente Emparán) hasta el 2 de marzo de 1811 , fecha del establecimiento del primer congreso constituyente.

E1 19 de abril, la Junta Suprema convocó a los pueblos a elecciones generales. La alocución que Juan Germán Roscio dirigió a los mismos el 10 de junio, y el reglamento correspondiente, redactados ambos por él, han sido estimados tanto fuente de legitimación del congreso general conservador de los derechos de Fernando VII en Venezuela, como origen del derecho electoral venezolano. 51

Sin embargo, las ciudades y pueblos del interior no tuvieron representación, mientras que los delegados de Caracas excedieron con mucho a los representantes del resto de la Capitanía General. El reglamento electoral reconoció el derecho de sufragio con las siguientes excepciones:

"las mujeres, los menores de veinticinco años, a menos que estuviesen casados $y$ velados, los dementes, los sordomudos, los que tuviesen causa criminal abierta, los fallidos, los deudores a caudales públicos, los extranjeros, los transeúntes, los vagos públicos y notorios, los que hubiesen sufrido pena corporal aflictiva o infamatoria, $y$ todos los que no tuviesen casa abierta o poblada, esto es, que viviesen en la de otro vecino particular a su salario y expensas o en actual servicio suyo, a menos que según la opinión común del vecindario fuesen propietarios por lo menos de dos mil pesos en bienes muebles o raices libres" 52 .

Se determinó que las elecciones se hiciesen en dos grados: en las parroquias y en las cabeceras de partidos capitulares.

También en la Constitución Federal de diciembre de 1811 la elección fue de dos grados: elección primaria o parroquial y elección capitular. En la primera tuvo derecho de voto todo hombre libre, ciudadano venezolano, vecino de la parroquia, mayor de veintiún años, siendo soltero, o menor siendo casado y velado, y se requirió además que poseyese bienes libres por valor de doscientos á seiscientos pesos, "según fuera soltero o casado y según se encontrasen los bienes en las capitales de provincia o en otras poblaciones; o que tenga grado en una ciencia o arte, o sea propietario o arrendador de tierras para sementeras o ganado, con tal que sus productos alcancen a la suma asignada para los respectivos casos de soltero y casado". No votarían: los dementes, los sordomudos, los fallidos, los deudores a caudales públicos con plazo cumplido, los extranjeros, los transeúntes, los vagos públicos y notorios, los que hayan sufrido infamia no purgada por la ley, los que tengan abierta causa criminal de gravedad, y los que siendo casados no vivan con sus mujeres sin motivo legal. Además de tener las cualidades requeridas para los sufragantes parroquiales, los electores de segundo grado debían ser vecinos del partido capitular donde votasen y poseer una propiedad libre de seis mil pesos en la capital de Caracas, siendo solteros y 6 propiedades de cuatro mil siendo casados. Esta propiedad se rebajaría a cuatro mil y tres mil, respectivamente, en las otras ciudades y villas.

51 Leal Curiel, Carole, "El Reglamento de Roscio y las elecciones de 1810: una convocatoria al a

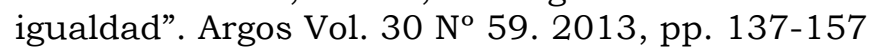

52 Gil Fortoul, José, Historia Constitucional de Venezuela. Tomo I. La Colonia. La Independencia. La Gran Colombia, Carl Heymann, Berlín, 1907. 


\subsection{Mérida y Trujillo: constituciones y contextos.}

De las siete provincias que declararon la Independencia en 1811, únicamente las de Mérida, Trujillo y Caracas pudieron darse constituciones propias. Las de Cumaná, Margarita, Barcelona y Barinas se vieron envueltas en la guerra contra España antes de terminar su organización constitucional. Las de Coro, Maracaibo y Guayana permanecieron dominadas por las armas realistas.

La ciudad de Mérida, el 16 de setiembre de 1810, se comprometió con la sublevación del 19 de abril, se apartó del Gobierno de Maracaibo y formó una Junta a la que se sometieron las ciudades de la Grita y San Cristóbal. ${ }^{5}$

Mérida pertenecía en 1810 a la provincia de Maracaibo, que se mantuvo realista después de la revuelta caraqueña de 1810. Mérida en principio siguió fiel al rey, pero Caracas envió a un representante, D. Luis María Rivas Dávila, quien persuadió a los merideños. En septiembre se apartó del gobierno de Maracaibo y convocando Cabildo Abierto, formó su propia Junta "cesando por consiguiente todas las autoridades superiores, e inferiores que hasta el dia de hoy han gobernado, las que deben centralizarse en la enunciada Junta.", junto con las ciudades de La Grita y San Cristóbal.

Mariano de Talavera y Garcés fue nombrado vicepresidente de la Junta Provincial de Mérida y remitió una carta a la Junta Suprema de Caracas, que apareció publicada el martes 9 de octubre de 1810, en la que recibía con beneplácito la noticia de los sucesos del 19 de abril de 1810 e informaba sobre la instalación de una Junta depositaria y la separación de la Ciudad de Mérida de Maracaibo. Talavera, al tiempo, solicitó ayuda al Marqués del Toro, para que enviase algunos ejércitos, ante las pretensiones hostiles que pudiera tener la ciudad de Maracaibo. ${ }^{54} \mathrm{Y}$ todo a pesar de la desconfianza manifiesta y el rechazo a la hegemonía mantuana entre las élites dirigentes de ciudades de la región occidental y central de la capitanía general. ${ }^{55}$

Sin embargo, la imposibilidad por Caracas de enviar ayuda militar y el avance de las tropas de Maracaibo al mando de Ramón Correa provocarían finalmente la dimisión de los mandos republicanos, su procesamiento y la consolidación de un fuerte grupo realista en la ciudad.

La élite meridense percibió como inminente el ataque de Maracaibo, ciudad con la que mantenían una centenaria disputa desde que en 1678 Mérida perdiera la capitalidad de la provincia. Algunos historiadores han fundamentado la rencilla permanente entre ambas ciudades en la pugna por hacerse con la titularidad del obispado creado en 177756. Reunidos en Mérida, Venezuela, el 21 de julio de 1811, los representantes de los partidos capitulares sancionaron el 31 de agosto una constitución provincial, que debía regir provisionalmente hasta que

53 Montoya, Miguel, Evolución politico-territorial de Mérida (1558-1914), Universidad de los Andes, Mérida, 2008, p. 125.

54 Hernández Bencid, María Soledad, "Periodismo criollo en 1808: Monseñor Mariano de Talavera y la Gaceta de Caracas”, Tierra Firme, v.24, n.96, Caracas, dic. 2006.

55 Hernández González, Manuel, Entre la insurgencia y la fidelidad. Textos canarios sobre la Independencia venezolana, Idea, Tenerife, 2010, p. 53.

56 González Sierralta, Hacer, Documentos para el estudio de Mérida durante la campaña admirable 1813, FUNDECEM, Caracas, 2014, p. 20. 
el congreso instalado en Caracas dictase la carta de la Confederación. Los legisladores merideños establecieron el sufragio universal, sin exigir a ningún sufragante la condición de propietario o rentista. En las elecciones primarias, para nombrar "apoderados" (en electores parroquiales), votarian todos los vecinos casados y los solteros de veintiún años, "con tal que - dice la constitución fueran personas libres, que no tengan causa criminal pendiente, ni hubieran sufrido pena infamatoria, y que estén en su cabal juicio, por cuya razón los locos, mentecatos, sordomudos y los que se han abandonado a la bebida, carecerán de voto". 57

Sin embargo, la constitución provisional de la provincia de Trujillo, sancionada el 2 de setiembre de 1811, contrastó con la de Mérida por su forma confusa y ampulosa y fue menos democrática58. Efectivamente, el cabildo de Trujillo declaró la independencia de Maracaibo el 9 de octubre de 1810 y el 2 de septiembre de 1811 proclamó la primera constitución. Con un Ejecutivo "Cuerpo Superior de Gobierno" compuesto por cinco vecinos beneméritos a los que en casos de extrema gravedad podían sumarse dos o tres más: todos vecinos de la provincia, mayores de 25 años y propietarios o con renta suficiente para mantenerse. Este cuerpo superior además ejercería el poder judicial como tribunal de apelaciones a las sentencias de los tribunales inferiores. ${ }^{59}$

Trujillo, sin la amenaza directa de Maracaibo, con el apoyo de Barinas, con una élite más conservadora que la merideña y con unos sectores populares sometidos, restringió al máximo la posibilidad de ostentar responsabilidades politicas. La Junta trujillana se caracterizó por sus problemas y confrontaciones internas entre los vocales, de tal forma que el capitán Manuel Delgado Moreno tuvo que ser enviado desde Caracas con el cargo de comandante militar de Trujillo para evitar que, con motivo de las rencillas internas, se perdiera a manos de los realistas. Delgado disolvió la Junta y nombró una nueva. ${ }^{60}$

De cualquier forma, Maracaibo reaccionó y tras una derrota inicial ante la alianza de trujillanos y barineses en diciembre de 1811, en marzo de 1812 los patriotas trujillanos fueron derrotados por los realistas marabinos y muchos de ellos fusilados sumariamente. El coronel Pedro Fernández, nombrado jefe militar y político persiguióá a todos los vinculados con la proclamación de independencia del 9 de octubre, confiscando sus bienes, encarcelándolos y/o fusilándolos. ${ }^{61}$

En el territorio de la Nueva Granada, en el Acta constitucional del Socorro ya se dejó traslucir un obstinado apartamiento del pueblo llano al goce de su espacio político. En su artículo 8 se indicó que "los representantes del pueblo serán elegidos anualmente por escrutinio a voto de los vecinos útiles (sin definir "útil" pero quedó perfectamente entendido), y sus personas serán sagradas e

57 Chalbaud Zerpa, Carlos, Historia de Mérida, Consejo de Publicaciones de la Universidad de los Andes, Mérida, 1997, pp. 95-127.

58 Gil Fortoul, José, Historia Constitucional de Venezuela, Parra León Hermanos, Caracas, 1930, pp. 173-176.

59 Brewer-Carias, Allan R., Sobre el constitucionalismo hispanoamericano pre-gaditano: 18111812, editorial jurídica venezolana, Caracas, 2013, p. 94.

60 Dávila, Vicente, Próceres Trujillanos, Imprenta Bolivar, Caracas, 1921, p. 111.

61 Briceño Perozo, Mario, Historia del Estado Trujillo, Academia Nacional de la Historia, Caracas, 1984, p. 53. 
inviolables. Los primeros vocales permanecerán hasta el fin del año de 1811", pero en sus artículos 11 y 12 se indicará que "Toda autoridad será establecida o reconocida por el Pueblo y no podrá removerse sino por la ley (no por el propio pueblo que la había elegido)" y el 12 "Solamente la Junta podrá convocar al Pueblo, y éste no podrá por ahora reclamar sus derechos sino por medio del Procurador General, y si algún particular osare tomar la voz sin estar autorizado para ello legítimamente, será reputado por perturbador de la tranquilidad pública y castigado con todo el rigor de las penas". ${ }^{62}$

\subsection{Santa Fe: desde el monarquismo hasta el independentismo.}

En la Nueva Granada, Santa Fe siguió un proceso similar al de Cartagena: se amplió el cabildo con diputados populares y fue purgado de vocales españoles, pero se formó una Junta de Gobierno que presidió el virrey Amar (represor del levantamiento quiteño de 1809 y perseguidor de los patriotas que tenían los ánimos más encendidos). La Junta de Gobierno, totalmente criolla, asumió el poder político y convocó a las ciudades dependientes del antiguo virreinato para organizar un Congreso Nacional. Así pues, el cabildo de Santa Fe decretó la noche del 20 de julio de 1810, la instalación de una Junta Suprema para el gobierno de la Nueva Granada, semejante a las que estaban funcionando en la peninsula. Alli se reconocía la autoridad de Fernando VII "siempre que venga a reinar entre nosotros" 63 , y se prometía acatamiento a las órdenes de la Suprema Junta de Regencia. Así pues, en este acto no aparecía la idea de independencia absoluta, pero sí se proclamaba el sistema federal a través de sus defensores más ilustres: José Acevedo Gómez y Camilo Torres. También como en Cartagena, a los pocos días fracasó la fórmula y el virrey y los oidores fueron destituidos y apresados por la presión popular, siendo enviados finalmente a España. ${ }^{64}$

La capital, Santa $\mathrm{Fe}$, se encontraba segura, protegida por el regimiento auxiliar de Santa Fe que al mando de Antonio Baraya se había situado al servicio de la causa patriótica. Como en Caracas o Quito, el intento de la élite capitalina de ser hegemónica en el resto del territorio de la jurisdicción conllevó recelos y desencuentros con el resto de las élites provinciales, pero Santa Fe se mostró segura de su poder y capacidad de extender su modelo centralista por el resto del territorio.

Producto de esta circunstancia, fue la constitución monárquica del 4 de abril de 1811 de Cundinamarca, con capital en Santa Fe de Bogotá. El único temor de Cundinamarca procedía del exterior: de la posible reorganización y ataque de tropas realistas remitidas desde España. Pero el peligro que acechaba se intuía tan lejano, que la constitución cundinamarquesa fue una de las más conservadoras y restrictivas, acorde con el espiritu general de la élite capitalina que la elaboró65. Se expuso en su título III, art. 8 que para ser miembro de la

62 Gutiérrez Ramos, Jairo, "Las juntas neogranadinas y el constitucionalismo criollo pregaditano", Procesos Revista Ecuatoriana de Historia, n 33, 2011, pp. 97-110.

63 Acta de Independencia (Acta del Cabildo Extraordinario de Santa Fe), 20 de julio de 1810. En https://goo.gl/5Cv25b

64 De la Vega, José, La Federación en Colombia, ediciones de la revista Bolivar Bogotá, 1952 , p. 42.

65 Cuño Bonito, Justo, Cundinamarca. Particularidades histórico-políticas de su formación, 2017, ESAP, Bogotá, pp. 163-189. 
representación nacional "se requiere de edad de veinticinco años cumplidos, dueño de su libertad, que no la tenga empeñada por precio, y si lo estuviere por voto se considerará absolutamente impedido para la parte ejecutiva y judicial". Tampoco podían ser miembros de la representación nacional los que tuvieran menos de seis años de vecindad "ni los que hubieran dado muestras positivas de ser opuestos a la libertad americana y transformación de nuestro gobierno ni los que se hallan baldados o lisiados (título III, artículo 8) o los de causa criminal pendiente, que hayan sufrido pena infamatoria, los fallidos voluntarios o alzados con hacienda ajena, los deudores del Tesoro, ni los sordo-mudos, dementes o mentecatos, ni los que sin justa causa están separados de sus mujeres, ni los que estando a servicio de otro, viven de ajenas expensas, ni los vagos y transeúntes (título XI, artículo 2). ${ }^{66}$

La Junta de Santa Fe, convertida en Estado de Cundinamarca el 30 de marzo de 1811 (día en que expidió su Constitución) presidida por Jorge Tadeo Lozano y atacada por Nariño desde su periódico "La Bagatela" fue la institución definitiva. Lozano, desacreditado por la debilidad de su gobierno, cedió el puesto a Nariño para presidir el Estado de Cundinamarca (19 de septiembre de 1811). En esta fecha ya estaban en la capital los diputados de siete provincias quienes firmaron el 27 de noviembre de 1811 el "Acta de Federación de las Provincias Unidas de la Nueva Granada", que consideraba en su preámbulo a dichas provincias reunidas en una asociación federativa, que remitiendo a la totalidad del gobierno federal las facultades propias y privadas de un solo cuerpo de nación, reservaba para cada una de las provincias su libertad, su soberanía y su independencia, en lo que no fuera del interés común, garantizándose a cada una de ellas estas preciosas prerrogativas y la integridad de sus territorios...". ${ }^{67}$

Cundinamarca con su constitución del 4 de abril de 1811 se situaba en contra del resto de las provincias en dos aspectos: en su idea de mantener un gobierno individuado ${ }^{68}$ dependiente aún del poder metropolitano, como recogía en el articulado de su Título Primero, y en la visión unilateral de un poder político que consagraba el espíritu elitista centralista observado en la Junta. De este modo, mientras en las constituciones de Cundinamarca o Mariquita, el artículo referente a la libertad individual sólo indicó que: "La igualdad consiste en que siendo los hombres iguales en naturaleza lo son también delante de la ley", en algunos de los textos constitucionales más progresistas, como el de la República de Tunja, el del estado de Cartagena o en el de Antioquia, se atacó explícitamente la base misma de la desigualdad: aquella derivada de la herencia o del nacimiento.

Posteriormente la élite cundinamarquesa advertiría la imposibilidad de continuar impulsando una obra legislativa basada en principios monárquicos y republicanos, al mismo tiempo, aunque mantuvo su carácter exclusivista y excluyente. Nariño, presidente del Estado e investido de facultades

66 Pombo, Manuel Antonio y Guerra, José Joaquín, Constituciones de Colombia. Tomo I, Biblioteca Banco Popular Bogotá, 1986, pp. 307-379.

67 Gutiérrez Ardila, Daniel. Un Nuevo Reino. Geografia, Politica, Pactismo y Diplomacia Durante el Interregno en la Nueva Granada 1808-1816, Universidad Externado de Colombia, Bogotá, 2010.

68 Se toma el término "individuado" del Diccionario de Autoridades (1734) a partir de su acepción "Lo assí singularizado y tratado con particularidad". Se maneja el término sustituyendo al anacronismo "autónomo", inexistente en la época. 
extraordinarias, abandonó la constitución de abril de 1811, convocó nuevas elecciones y se dispuso a reformar el texto constitucional. El serenísimo colegio revisor y electoral comenzó sus sesiones el 23 de diciembre de 1811 y el 17 de abril de 1812 fue expedida la nueva constitución. Esa nueva constitución rechazó la envoltura monárquica y optó por una forma absolutamente republicana donde, a menudo, la constitución de Tunja recién expedida impuso su lenguaje y sus formas. En el título "De los Derechos del Hombre y sus Deberes" se indicará, artículo 4, que "el pueblo es la universalidad de los ciudadanos, y ninguna parcialidad de gentes puede arrogarse el nombre de pueblo". En el artículo 10 se indicará que "la soberanía, residiendo en la universalidad de los ciudadanos, es una, indivisible e inajenable" y en el 24 que "Los indios gozan de todos los derechos de ciudadanos, y tienen voz y voto en todas las elecciones, como los demás de esta república". Sin embargo, se establecería una dura limitación general para el goce efectivo de los derechos políticos: en el título "Deberes del Ciudadano", artículo 30 se indicará que "todo ciudadano desde la edad de quince años hasta la de cuarenta y cinco, para gozar de los derechos de tal, deberá inscribirse en la lista militar de la nación". En este sentido, en el título VIII "De la Fuerza de Armada", se indicaría, artículo 2, que "todo ciudadano es soldado nato de la patria mientras que sea capaz de llevar las armas, sin distinción de clase, edad o condición, y nadie puede eximirse del servicio militar en las graves urgencias del Estado, cuando peligra la patria". Frente a esta universalidad para formar parte del ejército, la participación politica fue mucho más restrictiva. En el título XI "De las Elecciones Primarias", se indicaría (artículo 1) que para gozar del "precioso derecho de sufragio en las elecciones primarias" había que tener 21 años y estar inscrito en la lista cívica, vivir de su renta y trabajo y también podrían gozar del derecho los menores de veintiún años casados y velados. Sin embargo, no gozarian del derecho (artículo 2, copia del título XI, artículo 2 de la anterior constitución) "los que tienen causa criminal pendiente, ni los que hayan sufrido pena infamatoria, ni los fallidos voluntarios o alzados con hacienda ajena, los deudores del Tesoro, ni los sordo-mudos, dementes o mentecatos, ni los que sin justa causa están separados de sus mujeres, ni los que estando a servicio de otro, viven de ajenas expensas, ni los vagos y transeúntes". Como elemento nuevo, no copiado de la anterior constitución, en este mismo artículo se indicaria que "todos los que se hallaren con alguna de las notas dichas en este artículo carecen de voz activa y pasiva en todas las elecciones". Sólo aquellos que vivieran de su renta y su trabajo pero que no estuvieran al servicio de otro, podrian ser sujetos de derechos políticos.

\subsection{Tunja: entre las amenazas internas y externas.}

Como hemos indicado, la de Tunja fue modelo para este tipo de constitución más progresista y garantista de los derechos de libertad e igualdad de todos los ciudadanos. La élite tunjana observaba con temor, a una distancia de tan sólo 150 kilómetros, el poder militar de Cundinamarca, y sabía que, ante la posibilidad de inestabilidad externa, debía asegurar la tranquilidad interna en una población mayoritariamente indígena. 69

\footnotetext{
69 La región era la que concentraba mayor cantidad de población indigena de todo el virreinato. Pese a la catástrofe demográfica analizada por Colmenares, Friede, Jaramillo o Melo para los siglos XVI y XVII (se calculó una población indígena de entre 3 y 6 millones de habitantes de la
} 
Así, en su Capítulo I, artículo 4, la constitución de Tunja del 9 de diciembre de 1811 indicó que "Ningún hombre, ninguna corporación o asociación de hombres tiene algún título para obtener ventajas particulares o exclusivos privilegios distintos de los que goza la comunidad, si no es aquel que se derive de la consideración que le den sus virtudes, sus talentos y los servicios que haga, o haya hecho al público. Y no siendo este título por su naturaleza hereditario ni transmisible a los hijos, descendientes o consanguíneos, la idea de un hombre que nazca Rey, Magistrado, Legislador, o Juez, es absurda y contraria a la naturaleza". En el 19 se afirmó que "la universalidad de los ciudadanos constituye el Pueblo Soberano" y en el 23 que "Todas las elecciones deben ser libres, y cada ciudadano tiene un derecho igual de concurrir, mediata o inmediatamente, a la formación de las leyes, al nombramiento de los representantes o funcionarios públicos". También en su Título I, artículo 26 "Todo gobierno se ha establecido para el bien común, para la protección, seguridad y felicidad del pueblo, y no para el provecho, honor o interés particular de ningún hombre, familia o clase de hombres..." y en el artículo 27 "Todos los reyes son iguales a los demás hombres y han sido puestos sobre el trono por la voluntad de los pueblos para que los mantengan en paz, les administren justicia y los hagan felices".

Con respecto a la constitución de Cundinamarca, en la de Tunja no se excluía de los órganos de representación a los ciudadanos que vivieran a expensas de otros. En la Sección Primera, Capítulo 1, artículo 5, se indicó que "Los individuos que se elijan para esta corporación deben tener residencia lo menos un año, veinte años de edad y un oficio honesto de donde se mantengan por sí". Sí quedaron excluidos para el Senado aquellos ciudadanos sin una propiedad de dos mil pesos o que pudieran dar una fianza equivalente y para ocupar los más altos cargos (gobernador o teniente gobernador) se requirió una renta de cuatro mil pesos. Sin embargo, los electores encargados de seleccionar a los ciudadanos que formarian parte del Congreso Electoral encargado de elegir a los representantes del Congreso General no sólo no tuvieron que gozar de una renta fija, sino que se especificó (Sección 7, artículo 7) que "Para el nombramiento de electores pueden votar todos los vecinos que, pasando de quince años, tengan

cual fue aniquilada dos terceras partes), se han especulado con la posibilidad de una recuperación durante todo el siglo XVIII.

Jaramillo Uribe, Jaime, "La población indígena de Colombia en el momento de la conquista y sus transformaciones posteriores", Anuario Colombiano de Historia Social y de la Cultura, [S.1.], n. 2, jan. 1964, pp. 239-293.

Orlando Melo, Jorge, Historia de Colombia, La Carreta, Bogotá, 1978.

Tovar Pinzón, Hermes, "Estado actual de los estudios de demografia histórica en Colombia", Anuario Colombiano de Historia Social y de la Cultura, no. 5, 1970.

Colmenares, Germán, Historia económica y social de Colombia, 1537-1719, Editorial La Carreta, Medellin, 1975.

Friede, Juan, "Algunas consideraciones sobre la evolución demográfica en la Provincia de Tunja”, Anuario Colombiano de Historia Social y de la Cultura 2, no.3, 1965.

Suescún, Armando, Constitución de la República de Tunja de 1811, Academia Boyacense de Historia, Tunja, 2011, pp. 18-46. 
un oficio honesto de que se mantengan por sí, y no tengan las tachas que se han expresado para los representantes"70.

Tendremos así, una constitución, la de Cundinamarca, conservadora, excluyente, elaborada por una élite que se siente segura y defendida. La de Tunja, abierta a todos los sectores sociales por una élite que se siente amenaza en el exterior y que por ello busca la paz interna. Y tendremos otra constitución, la de Cartagena, más abierta (siempre teóricamente) que la cundinamarquesa a la participación política de varios sectores sociales, pero menos que la tunjana y dentro de una sociedad conservadora y temerosa de la reacción de la corona, encarnada en la amenaza del enclave realista de Santa Marta distante a unos 200 kilómetros de distancia.

Aunque la independencia de Cartagena el 11 de noviembre de 1811 fue una conquista de los sectores populares ante la pacatería de las élites conservadoras, estas reaccionaron haciéndose con el control político del Estado nombrando dictador a Manuel Rodríguez Torices. El análisis de José Manuel Restrepo al respecto no pudo ser más esclarecedor:

"El pueblo de la ciudad de Cartagena habia hecho una revolución. Como desde el principio fue llamada la plebe a tomar parte en los movimientos a fin de echar por tierra al partido real, ella se insolentó; y la gente de color, que era numerosa en la plaza, adquirió una preponderancia que con el tiempo vino a ser funesta a la tranquilidad pública". ${ }^{71}$

Efectivamente sólo con la ayuda de los cañones robados que los pardos de Getsemaní orientaron en dirección al cuartel del fijo, la Junta quiso escuchar y acceder a las peticiones de Ignacio Muñoz y de Nicolás Mauricio de Omaña: que la provincia de Cartagena fuese declarada Estado soberano e independiente, que se extinguiera el tribunal de la Inquisición, franqueándose pasaportes a los inquisidores para que saliesen del país; que los empleos del consulado y del regimiento Fijo se dieran a los Americanos; que se dividiesen los poderes legislativo, ejecutivo y judicial ejercidos por la junta; que cesara la pesquisa contra los que hicieron la revolución de Mompox, declarándose nulo cuanto el comisionado Ayos había practicado contra ellos y finalmente, que al gobierno de Cundinamarca se le entregaran los fusiles que injustamente se le habian retenido. Lo realmente extraordinario es que las peticiones no suponian una revolución social ni política de gran calibre sino la petición de transformaciones moderadas, progresivas que permitieran, en primera instancia, consolidar un proyecto político fuerte y al margen de la legalidad institucional emanada desde la península.

\subsection{De Cartagena de Indias a Cúcuta: de la incertidumbre a la consolidación en el poder.}

En la constitución de Cartagena de Indias del 14 de junio de 1812 en su Título I, Artículo 8 se expuso que "De la esencia y constitutivo de la sociedad se deduce que ningún hombre, corporación o asociación de hombres tiene otro título

70 Pombo y Guerra, Constituciones de Colombia, Op. Cit., 1986, t. I, pp. 421-465

71 Restrepo, José Manuel, Historia de la Revolución de Colombia, Tomo III, Librería Americana, París, 1827, pp. 42-47. 
para obtener ventajas o derechos particulares o exclusivos, distintos de los de la comunidad, que el que dimana de la consideración de servicios hechos al Estado. Y no siendo este título por su naturaleza, ni hereditario ni transmisible a hijos, es absurda y contra la naturaleza la idea de un hombre privilegiado hereditariamente o por nacimiento, y exacta, justa y natural la idea de la igualdad legal; es decir, de la igualdad de dependencia y sumisión a la ley de todo ciudadano, e igualdad de protección de la ley a todos ellos.".

Sin embargo, ese mayor conservadurismo de la constitución cartagenera que fue el resultado de la negociación entre élites conservadoras y representantes de sectores populares se evidenció en su Preámbulo, artículo 14, cuando se indicó que para elegir y ser elegidos los habitantes del Estado tendrian que poseer las cualidades exigidas por la propia Constitución y por el desempeño de los empleos. Entre otras, las cualidades necesarias para poder ejercer el derecho de elegir a sus representantes fueron las de ser (Título IX, artículo 1): "hombre libre, vecino, padre o cabeza de familia, o que tenga casa poblada y viva de sus rentas o trabajo o sin dependencia de otro". Añadió, además, que quedaban excluidos los esclavos y los asalariados. A los altos cargos del ejecutivo o del legislativo no se les exigió renta alguna de manera explícita, pero se acotó de manera determinante el acceso a los altos cargos: sólo pudieron acceder aquellos (Título V, artículo 26 y Título VIII, artículo 5.) con "un manejo, renta o provento bastante para subsistir con comodidad".

Como fruto de esa negociación entre las distintas élites políticas, el título XIII artículo 2, prohibió toda importación de esclavos en el Estado como objeto de comercio; el artículo 4 previó la creación de un fondo de manumisión; el 5. otorgó al Cuerpo Legislativo la tarea de cuidar que la protección de las leyes defendiera a los esclavos de la arbitrariedad e inclemencia de sus propietarios y, según el artículo 7, comprometió al mismo Cuerpo Legislativo a cuidar de los pobres en general mediante la creación de instituciones de beneficencia.

Para controlar a los sectores políticos más radicales e intentar evitar en el futuro sobresaltos, la élite conservadora, en el artículo 14, estipuló que la reunión de gentes, armadas o sin armas, si con tumulto o desorden amenazaban la seguridad pública, sería dispersada primero por una orden verbal y no bastando, por la fuerza ${ }^{72}$.

Pero en todos estos territorios, una vez que estas élites, finalizado el conflicto de independencia, se asentaron en el poder, ya fue posible prescindir de los artículos más incómodos y que menos reflejaban el proyecto de Estado que se pretendia construir: la constitución provisional de la Provincia de Antioquia de 1815 eliminó de su articulado la referencia (explícita en la primera constitución) a la libertad de imprenta y las referencias a la seguridad y a la propiedad sustituyeron los encendidos artículos que en 1812 habían atacado la desigualdad. 73

En la villa de Cúcuta el primer Congreso Constituyente de una Colombia ya independiente se instaló el 6 de mayo de 1821. Las elecciones -indicó el texto constitucional- se practicarian en asambleas parroquiales y en asambleas

72 Pombo y Guerra, Constituciones de Colombia, Op. Cit., 1986, t. I, pp. 92-169.

73 Restrepo Piedrahita, Carlos, Constituciones de Colombia, Biblioteca Banco Popular, Bogotá, 1986, p. 307. 
electorales o de provincia (Título III, Sección I, artículos 12, 13, 14 y 15). Las primeras votarian por el elector o electores que correspondan al cantón (uno por cada cuatro mil almas, y otro más por un residuo de tres mil); las segundas, por el presidente y vicepresidente de la República, senadores y diputados. Para ser sufragante parroquial se requirió: ser colombiano, casado o mayor de veintiún años, dueño de una propiedad raíz del valor libre de cien pesos, o ejercer oficio, profesión, comercio o industria útil con casa o taller abierto, sin depender de otro como jornalero o sirviente. La condición de saber leer y escribir se aplazó hasta el año de 1840. Para ser elector fue preciso: ser sufragante parroquial no suspenso, mayor de veintiún años y vecino del cantón, dueño de una propiedad raíz que valiera quinientos pesos, o empleado público o usufructuario de bienes con renta anual de trescientos pesos, o profesor de alguna ciencia, o graduado en la misma. ${ }^{74}$

\section{CONCLUSIONES}

Pese a que en medio del fragor de la batalla contra el absolutismo todas las posibilidades estuvieron abiertas, lo probable, en forma de fuertes restricciones al ejercicio de elección y participación política, fue lo que acabó imponiéndose. Sólo una élite privilegiada asumió el ejercicio de la hegemonía política, limitando la participación de una inmensa mayoría de la población, que transitó desde la colonia hasta la república sin variar visiblemente su estatus. Como hemos indicado, los argumentos esgrimidos por esa élite fueron casi copiados de los esgrimidos por las autoridades absolutistas para restringir los derechos politicos de esa misma élite: la referencia a un estado de inmadurez o de incapacidad para regir sus propios destinos, fueron frecuentes y legitimaron el ejercicio autocrático de la política. Y todo ello, pese a que el esfuerzo fiscal y la generosidad en la entrega de sus vidas a la causa republicana por parte del pueblo llano resultaron decisivos para el triunfo de las armas patriotas. La investigación evidencia que los grados de participación política reconocidos en los textos constitucionales a ese mismo pueblo llano, estuvieron vinculados a los contextos sociales, políticos y militares donde emergieron estos proyectos políticos: los peligros internos o externos flexibilizaron los espacios de participación política y ampliaron o disminuyeron las posibilidades de que a la gente del común les fueran reconocidos derechos de ciudadanía. Una vez asentados en el poder, los miembros de las élites buscaran restringir aún más los espacios de participación política, asentar más firmemente su dominación y sustituir el ejercicio coactivo de los medios de dominación por otros simbólicos que obtuviesen los mismos resultados, pero de manera más sutil. Desde entonces, el Estado no será, pues, un mero instrumento de dominio: la hegemonía de una clase implicaba tanto dirección ideológico-política de la sociedad civil, como la combinación de fuerza y consenso. Enfatizar más en una u otra dependería, como siempre, del contexto en el cual se ejerciera el proceso de dominación. ${ }^{75}$

\section{Bibliografia}

\footnotetext{
74 Pombo y Guerra, Constituciones de Colombia, Op. Cit., 1986, t. I, pp. 68-104

75 Gramsci, Antonio, ¿Qué es la Cultura Popular?, Universitat de València, Valencia, 2012, p. 33
} 
Blanco Valdés, Roberto L., La construcción de la libertad. Apuntes para una historia del constitucionalismo europeo, Alianza Editorial, Madrid, 2010.

Bohórquez Morán, C. L., Francisco de Miranda. Precursor de las independencias de la América Latina. Editorial de Ciencias Sociales, La Habana, 2003.

Grau, Luis, Nosotros, el Pueblo de los Estados Unidos. La Constitución de los Estados Unidos y sus enmiendas 1787-1992, Universidad Carlos III, Madrid, 2010.

Rubio Carracedo, José, "La nueva constitución política de Rigas Velestinlins", Revista de Estudios Políticos (Nueva Época), Núm. 105. Julio-Septiembre 1999, p. 295-308.

Zea, Francisco Antonio, Manifiesto a los Pueblos de Colombia, en http://www.cervantesvirtual.com/obra/manifiesto-sobre-la-creacion-de-larepublica-de-colombia--0/

Abella, Gonzalo, Artigas el Resplandor Desconocido, Betum San Ediciones, Montevideo, 1999.

Acevedo-Tarazona, Álvaro y Villamizar-Palacios, Carlos "La soberanía local durante la primera época republicana en el Nuevo Reino de Granada. Los casos de Tunja, Socorro y Mariquita, 1810-1812", HiSTOReLo. Revista de Historia Regional y Local 12 (23), 2020, pp. 157-189.

Acta de Independencia (Acta del Cabildo Extraordinario de Santa Fe), 20 de julio de 1810. En https://goo.gl/5Cv25b

Actas del Consejo, 1.808. Archivo Municipal de Quito

Alegre, María "El voto de las mujeres en la Argentina". En Peña González, Patricia y Zamorano, Paulina, Mujeres ausentes Miradas Presentes, Universidad de Santiago de Chile, Santiago de Chile, 2002.

Ali, Omar H. Abolicionismo en América: Hacia un Estudio Comparativo de Historia Mundial, Pontificia Universidad Javeriana, Bogotá, 2005.

Annino, Antonio (Coord.), Historia de las elecciones en Iberoamérica, siglo XIX, Buenos Aires, Fondo de Cultura Económica, 1995.

Archivo General de la Nación de Colombia, Fondo José Manuel Restrepo, Rollo 5, Documentos relativos a la ocurrencia del 17 de diciembre último y sus resultados.

Arias Bautista, María Teresa, "Los Principios de Olympe de Gouges: culminación de una ideología revolucionaria", Revista Internacional de Culturas y Literaturas, Grupo de Investigación y Escrituras, Universidad de Sevilla, $\mathrm{n}^{\circ}{ }_{1}$, 2012, pp. 2-7.

Bello, Eduardo, "El poder y los poderes en la Constitución de 1791", en Bello, Eduardo (Ed.), Filosofia y Revolución, Universidad de Murcia, Murcia, 1991, pp. 35-76.

Blossom, Thomas, Nariño, hero of Colombian independence, University of Arizona Press, Tucson, 1967. 
Bonilla Vélez, Gloria, "La lucha de las mujeres en América Latina: Feminismo, Ciudadanía y Derechos" Revista Palobra palabra que obra. DOI:10.32997/23462884-vol.8-num.8-2007-225, 2007, pp. 42

Brewer-Carias, Allan R., Sobre el constitucionalismo hispanoamericano pregaditano: 1811-1812, editorial jurídica venezolana, Caracas, 2013, p. 94.

Briceño Perozo, Mario, Historia del Estado Trujillo, Academia Nacional de la Historia, Caracas, 1984, p. 53.

Chalbaud Zerpa, Carlos, Historia de Mérida, Consejo de Publicaciones de la Universidad de los Andes, Mérida, 1997, pp. 95-127.

Chiaramonte, José Carlos, "El antiguo constitucionalismo en la historia hispanoamericana del siglo XIX", Nuevo Mundo Mundos Nuevos, [En ligne], Débats, mis en ligne le 08 octobre 2020, consultado el 03 enero 2021. URL : http://journals.openedition.org/nuevomundo/81983

Chiaramonte, José Carlos, "Vieja y nueva representación: los procesos electorales en Buenos Aires, 1810-1820", en Annino, Antonio (Coord.), Historia de las elecciones en Iberoamérica, siglo XIX, Buenos Aires, Fondo de Cultura Económica, 1995, pp. 19-63.

Chust, Manuel, José Mejía Lequerica: diputado del Nuevo Reino de Granada a las Cortes de Cádiz, en VV.AA., La Independencia en los Países Andinos: Nuevas Perspectivas, Universidad Andina Simón Bolivar/OEI, Quito, 2004.

Chust, Manuel, y Ivanna Frasquet, "La génesis de las independencias. La complejidad de un proceso histórico de dimensiones universales", en Chust Manuel y Frasquet, Ivana (Eds.), La patria no se hizo sola. Las revoluciones de independencia iberoamericanas, Sílex, Madrid, 2012, pp. 17-66.

Chust, Manuel, 1812, El poder de la palabra, Acción Cultural Española, 2012.

Chust, Manuel, La Tribuna Revolucionaria: La Constitución de 1812 en ambos hemisferios, Sílex, España, 2014.

Clausewitz, Karl Von, De la Guerra, Labor, Barcelona, 1994.

Clavero Salvador, Bartolomé, "Constitución Europea e Historia Constitucional. El rapto de los poderes", Crónica Jurídica Hispalense: revista de la Facultad de Derecho, $\mathrm{n}^{\circ}$ 3, 2005, pp. 459-478.

Colmenares, Germán, Historia económica y social de Colombia, 1537-1719, Editorial La Carreta, Medellín, 1975.

Constant de Rebecque, Benjamin, Principios de politica aplicables a todos los gobiernos, Katz Editores, Madrid, 2010.

Constitución Francesa de 3 de septiembre de 1791, en http:/ /hc.rediris.es/01/Constituciones/cf1791.htm

Constitution du 24 juin 1793 en http://www.conseilconstitutionnel.fr/conseil-constitutionnel/francais/la-constitution/lesconstitutions-de-la-france/constitution-du-24-juin-1793.5084.html 
Cuño Bonito, Justo y Carrillo García, Germán, "Sobre la élite que forjó la nación latinoamericana y las fronteras a los derechos de ciudadanía (17781823)", en Soto Acosta, Willy. Repensar las fronteras, la integración regional y el territorio. Buenos Aires: CLACSO, 2017, p. 29.

Cuño Bonito, Justo, "La construcción política de una compleja realidad social: Conflictos, negociaciones y acuerdos en la base del primer constitucionalismo americano, 1811-1815", en Frasquet Miguel, Ivana y García Monerris, Encarnación, Tiempo de Política, tiempo de constitución: la monarquía hispánica entre la revolución y la reacción (1780-1840), Comares, 2018, pp. 27-54.

Cuño Bonito, Justo, "Los nuevos Estados nacionales y los debates en torno a la abolición de la esclavitud en América Latina: 1815-1860", en Naranjo Orovio, Consuelo, Esclavitud y diferencia racial en el Caribe hispano, Doce Calles, Madrid, 2017, p. 185

Cuño Bonito, Justo, Cundinamarca. Particularidades histórico-políticas de su formación, 2017, ESAP, Bogotá, pp. 163-189.

Cuño Bonito, Justo, El Retorno del Rey, Universidad Jaume I, Castellón, 2018.

Dávila, Vicente, Próceres Trujillanos, Imprenta Bolivar, Caracas, 1921, p. 111.

De la Vega, José, La Federación en Colombia, ediciones de la revista Bolivar Bogotá, 1952, p. 42.

De Tocqueville, Alexis, El Antiguo Régimen y la Revolución, Alianza Editorial, Madrid, 1994.

Declaración de Derechos del Hombre y del Ciudadano de 1793. 1877. Incluida en Les Déclarations des Droits de L'Homme et du citoyen. 1789-1791-1793-1795. 8-12, París: Sandoz et Fischbacher. Acceso el 10 de febrero de 2020. https://gallica.bnf.fr/ark:/12148/bpt6k54716008/f7.image

Duverger, Maurice, Instituciones politicas y Derecho Constitucional, Ariel, Barcelona, 1970.

Elorza, Antonio, La Ideología Liberal en la Iustración Española, Tecnos, Madrid, 1970.

Eslet Shoubens, Osiris, "La fraternidad, arma positiva del pueblo haitiano", en Duffard Evangelista, Irene y Rodríguez Caguana, Adriana. Atravesando Fronteras. Voces desde Haiti hacia Sudamérica, Universidad Andina Simón Bolivar, Quito, 2019. p. 68

Fernando Prado, David "Las mutaciones del Cabildo de Popayán en un periodo revolucionario, 1809-1811", Anuario Colombiano de Historia Social y de la Cultura 47.1, 2020, pp. 113-137.

Friede, Juan, "Algunas consideraciones sobre la evolución demográfica en la Provincia de Tunja", Anuario Colombiano de Historia Social y de la Cultura 2, no.3, 1965.

García, José Francisco, "El control de constitucionalidad en El Federalista y los fundamentos de una sociedad libre", Revista Chilena de Derecho, Vol. 30 NN $^{\circ}$, 2003, pp. 491-514.

Gil Fortoul, José, Historia Constitucional de Venezuela, Parra León Hermanos, Caracas, 1930, pp. 173-176. 
Gil Fortoul, José, Historia Constitucional de Venezuela. Tomo I. La Colonia. La Independencia. La Gran Colombia, Carl Heymann, Berlín, 1907.

González Sierralta, Hacer, Documentos para el estudio de Mérida durante la campaña admirable 1813, FUNDECEM, Caracas, 2014, p. 20.

Gramsci, Antonio, ¿Qué es la Cultura Popular?, Universitat de València, Valencia, 2012, p. 33

Grases, Pedro, La Conspiración de Gual y España y el Ideario de la Independencia, Instituto Panamericano de Geografia e Historia, Caracas, 1949.

Grases, Pedro, Pensamiento Politico de la Emancipación Venezolana, Biblioteca Ayacucho, 1988.

Guiomar, J. Y., La nation entre l'histoire et la raison, La Découverte, París, 1990.

Gutiérrez Ardila, Daniel. Un Nuevo Reino. Geografía, Politica, Pactismo y Diplomacia Durante el Interregno en la Nueva Granada 1808-1816, Universidad Externado de Colombia, Bogotá, 2010.

Gutiérrez Escudero, Antonio, "Un precursor de la emancipación americana: Antonio Nariño y Álvarez", Araucaria, Año 7, n 13, 2015.

Gutiérrez Ramos, Jairo “Acción política y redes de solidaridad étnica entre los indios de Pasto en tiempos de la independencia", Dossier. Siglo XIX: sociedad, política y religión, Historia Crítica, enero - junio 2007, Páginas 10-37.

Gutiérrez Ramos, Jairo "La constitución de Cádiz en la provincia de Pasto, Virreinato de la Nueva Granada, 1812-1822”, Revista de Indias, 2008, vol. LXVIII, núm. 242, Págs. 207-224.

Gutiérrez Ramos, Jairo, "Las juntas neogranadinas y el constitucionalismo criollo pregaditano", Procesos Revista Ecuatoriana de Historia, no 33, 2011, pp. 97-110.

Hamilton, A. Madison, J. y Jay J., El Federalista, Akal, Madrid, 2015.

Hernández Bencid, María Soledad, "Periodismo criollo en 1808: Monseñor Mariano de Talavera y la Gaceta de Caracas", Tierra Firme, v.24, n.96, Caracas, dic. 2006.

Hernández González, Manuel, Entre la insurgencia y la fidelidad. Textos canarios sobre la Independencia venezolana, Idea, Tenerife, 2010, p. 53.

Hernández, Guillermo (Comp.), Proceso de Nariño, t. I, Bogotá, Presidencia de la República, 1984, pp. 300-350.

Jaramillo Uribe, Jaime, "La población indígena de Colombia en el momento de la conquista y sus transformaciones posteriores", Anuario Colombiano de Historia Social y de la Cultura, [S.1.], n. 2, jan. 1964, pp. 239-293.

Kantorowitz, Ernst H., Los Dos Cuerpos del Rey: Un Estudio de Teología Politica Medieval, Alianza Editorial, Madrid, 1985.

Kossok, Manfred, "La Independencia en América Latina", en Roura, Lluís Y Chust, Manuel (Eds), La Iusión Heroica. Colonialismos, Revolución e Independencias en la obra de Manfred Kossok, Servicio de Publicacions de la Universitat Jaume I, Castelló de la Plana, 2010. 
Leal Curiel, Carole, "El Reglamento de Roscio y las elecciones de 1810: una convocatoria al a igualdad". Argos Vol. 30 N$^{\circ}$ 59. 2013, pp. 137-157

Ley de 11 de octubre de 1821, en: Codificación Nacional de todas las leyes de Colombia desde el año de 1821, Bogotá: Imprenta Nacional, 1924, tomo 1, pp. 116-118.

Lucas Verdú, Pablo, "Proclamación, formulación y significado de la Declaración de Derechos del Hombre y del Ciudadano de 1789", en García Herrera, Miguel Ángel (Coord.), Derechos Humanos y Revolución Francesa, Universidad del País Vasco, Bilbao, 1991, pp. 63-90.

Mairet, Gérard, "El liberalismo: presupuestos y significaciones”, en Châtelet, François y Mairet, Gerard (eds.), Historia de las Ideologías (507-524), Akal, Madrid, 1989.

Marchena Fernández, Juan. "Los pueblos andinos en su largo camino de siglos por la tierra y el respeto a su identidad", en Lucía Provencio (Ed.) Abarrotes: la construcción social de las identidades colectivas en América Latina, Universidad de Murcia, 2006, págs. 24 y ss.

Marie-Jean-Antoine Nicolas de Caritat, marqués de Condorcet, "Essai sur l'admission des femmes au droit de cité", 1790, citado en Paule Marie Duhet, Las Mujeres y la Revolución, Península, Barcelona, 1974.

Marquardt, Bernd, "Dos siglos de derechos fundamentales en Hispanoamérica (1810-2008). Exigencia y realidad desde una perspectiva global comparada", Revista Pensamiento Jurídico 23, 2008, pp. 33 - 72.

Martínez Ruiz Eduardo, La librería de Nariño y los Derechos del Hombre, Planeta, Bogotá, 1990.

Montoya, Miguel, Evolución politico-territorial de Mérida (1558-1914), Universidad de los Andes, Mérida, 2008, p. 125.

Morelli, Federica, "El Pacto quiteño de 1812: algunas reflexiones en torno al primer constitucionalismo ecuatoriano", en Ayala Mora, Enrique, Historia Constitucional. Estudios comparativos, Universidad Andina Simón Bolivar, Quito, 2014.

Orlando Melo, Jorge, Historia de Colombia, La Carreta, Bogotá, 1978.

Palacios, Nohora Patricia, "La elección de la república: historia de las elecciones en Colombia entre 1809-1838", tesis de doctorado en Estudios Políticos, París, École de Hautes Études en Sciences, Sociales, 2014.

Pérez Ramírez, Gustavo, Historia del Acta de la Independencia de Quito del 10 de agosto de 1809, FONSAL y Trama Ediciones Quito, Quito, 2009, p. 15.

Pérez Ramírez, Gustavo, La Revolución de Quito a la luz de nuevos documentos. 1809, Gobierno de la Provincia de Pichincha, Quito, 2010.

Pombo y Guerra, Constituciones de Colombia, Op. Cit., 1986, t. I, pp. 421-465

Pombo y Guerra, Constituciones de Colombia, Op. Cit., 1986, t. I, pp. 92-169.

Pombo y Guerra, Constituciones de Colombia, Op. Cit., 1986, t. I, pp. 68-104

Pombo, Manuel Antonio y Guerra, José Joaquín, Constituciones de Colombia. Tomo I, Biblioteca Banco Popular Bogotá, 1986, pp. 307-379. 
Posada Carbó, Eduardo (Dir.), Elections before Democracy: The History of Elections in Europe and Latin America, Londres, MacMillan Press, 1996.

Restrepo Piedrahita, Carlos, Constituciones de Colombia, Biblioteca Banco Popular, Bogotá, 1986, p. 307.

Restrepo, José Manuel, Historia de la Revolución de Colombia, op. cit., p. 115.

Restrepo, José Manuel, Historia de la Revolución de Colombia, op. cit. T. II, p. 120-130.

Restrepo, José Manuel, Historia de la Revolución de Colombia, Tomo III, Librería Americana, París, 1827, pp. 42-47.

Ribero, Darcy. Tiradentes. Joaquin Xosé Da Silva Xavier (1746 - 1792). http://www.portalalba.org.

Robespierre, M., Oeuvres complètes de Maximilien Robespierre, editado por la VI Section de l'École des Hautes Etudes y la Société des Études Robespierristes, a cargo de M. Bouloiseau, G. Lefebvre y A. Soboul, Presses Universitaires de France, París (1952-2007).

Robespierre, Maximiliano, Discursos e Informes en la Convención.: Editorial Ciencia Nueva S.L., Madrid. 1968.

Rodríguez Álvarez, Azucena, "Aproximación a la idea de "República" en la Francia Revolucionaria", Revista de Estudios Políticos (Nueva época), nº 91, 1996, pp. 201-215.

Rodríguez, Jaime E., "Los orígenes de la revolución de Quito en 1809", Procesos, Revista Ecuatoriana de Historia, No. 34 (jul. - dic. 2011), pp. 91-123.

Rodríguez, Jaime E., La Revolución Política durante la época de la independencia. El Reino de Quito. 1808-1822, Universidad Andina Simón Bolivar, Quito, 2006, pp. 70-79.

Rodríguez, Jaime, "Fronteras y conflictos en la creación de las nuevas naciones en Iberoamérica”, Revista Circunstancia, Año III - Número 9 - enero 2006.

Rodriguez-Toubes Muñiz, Joaquín, "Los textos ingleses sobre derechos fundamentales en el siglo XIX", en Historia de los derechos fundamentales / coord. por Francisco Javier Ansuátegui Roig, José Manuel Rodríguez Uribes, Gregorio Peces-Barba Martínez, Eusebio Fernández García, Vol. 3, Tomo 3, 2007 (El derecho positivo de los derechos humanos. Derechos humanos y comunidad internacional), Dykinson, Madrid, 2007, pp. 201-242

Romero, José Luis y Romero, Luis Alberto, Pensamiento Político de la Emancipación (1790-1825), Biblioteca Ayacucho, Caracas, 1977, pp. 167-176.

Saint - Just, Louis de, El Espiritu de la Revolución. Malinca Pocket, Buenos Aires, 1965.

Sánchez Albornoz, Nicolás. "Tributo abolido, tributo repuesto. Invariantes económicas en la Bolivia republicana" en Halperin Donhi, Tulio, el ocaso del orden colonial en Hispanoamérica, Buenos Aires, 1978 y Guerrero, Gustavo S., Documentos históricos de los hechos ocurridos en Pasto en la guerra de Independencia, Pasto, Imprenta del Departamento, 1912, pp. 52-53. 
Sánchez Quiñones, Luis, "Ciudadania, sufragio y propiedad en las Constituciones francesas de 1791 y 1793", Deusto Journal of Human Rights, No. 5/2020, 99-124.

Suescún, Armando, Constitución de la República de Tunja de 1811, Academia Boyacense de Historia, Tunja, 2011, pp. 18-46.

Tovar Pinzón, Hermes, "Estado actual de los estudios de demografia histórica en Colombia", Anuario Colombiano de Historia Social y de la Cultura, no. 5, 1970.

Tulard, Jean, Fayard Jean-François y Fierro, Alfred, Historia y Diccionario de la Revolución Francesa, Cátedra, Madrid, 1989.

Vanegas Useche, Isidro, "Elecciones y orden social en Nueva Granada, de la monarquía a la república", en Anuario Colombiano de Historia Social y de la Cultura 48.1, 2021, pp. 69-93.

Fecha de envío / Submission date: 14/04/2021

Fecha de aceptación / Acceptance date: 05/05/2021 